\title{
Internal donors on supported Ziegler Natta catalysts for isotactic polypropylene: a brief tutorial review
}

\author{
Bharat R. Paghadar ${ }^{1}$ J. B. Sainani ${ }^{1}$ - Samith K. M. ${ }^{1}$ Poornima Bhagavath ${ }^{2}$
}

Received: 31 March 2021 / Accepted: 29 August 2021 / Published online: 1 October 2021

(c) The Author(s) 2021

\begin{abstract}
The scientific and technical advances in the field of polymer science has been abundant in recent years. Amongst the various polymeric materials available in market, synthesis of polyolefins has been in the forefront since decades. A major challenge in this domain remains in attaining stereoregular polyolefins especially polypropylene (PP) and significant efforts were carried out by synthesizing various internal donors (ID) aiding the catalysts involved in producing them. This short review gives an overview of i) various generations of Ziegler-Natta (ZN) catalyst systems ii) general classes of ID that has been demonstrated by the researchers over the past decades iii) their influence on PP isotacticity and polymer properties. The coordination modes of different donor classes on supported ZN system and comparative study especially between phthalate and diether ID classes were also addressed here. This review also presents the studies carried out on phthalate catalyst structure analysis, detailed comparison study on phthalate and diether IDs in terms of PP isotacticity, regioselectivity, hydrogen response, and also their cross combination study and competitive behavior. Further a brief description on other structurally varied IDs like malonates, maleates, silyl diol esters, bifunctional donors, multi ether donors demonstrated for isotactic PP were also presented. Studies conducted on compatibility of incorporation of two different classes of IDs on a single supported $\mathrm{ZN}$ system for the fundamental understanding of the catalyst behavior; and also on how mixed donor approach enables in tuning the catalyst for polymer properties were also presented. This review also provides an opportunity to the young minds and the basic researchers from academic point of view by and large to create new polymeric materials with useful properties or modify the existing materials for new applications by incorporating new IDs for further improvisation of the stereo regularity in obtaining the polymers.
\end{abstract}

Keywords Internal donors $\cdot$ Ziegler Natta catalysts $\cdot$ Polypropylene $\cdot$ Isotacticity

\section{Introduction}

Polypropylene (PP) is one of the most widely used thermoplastic resins soaring over the past few decades due to its excellent performance [1]. The versatile nature of PP in terms of its stiffness, transparency, tensile strength, low production cost and ability to be recycled has made this PP to find numerous applications in a wide variety of fields like packaging industries, electrical, electronic, automobiles etc

Poornima Bhagavath

poornima.nayak@manipal.edu

1 PP Tech Polymer, SABIC Research and Technology Pvt. Ltd, Bengaluru, Karnataka, India

2 Department of Chemistry, Manipal Institute of Technology, Manipal Academy of Higher Education, Manipal 576 104, Karnataka, India
[2-5]. Generally, industrial manufacture of PP is derived from Ziegler Natta $(\mathrm{ZN})$ polymerization and $\mathrm{ZN}$ catalysts remain the top priority in the olefin polymerization industries [6-10]. For industrial application, mainly three different classes of PP derived from ZN Catalyst are homo, random $\mathrm{PP}$ and impact copolymer. Among homo $\mathrm{PP}$, isotactic polypropylene (iPP) has gained industrial importance owing to its extremely high stiffness leading to applications like injection molding, film, fiber etc. with the production of nearly 50 million tons/year over the world. Most of the commercial catalysts used for iPP manufacture are modified versions of original $\mathrm{ZN}$ system. The integral part of modified catalyst is $\mathrm{MgCl}_{2}$-supported $\mathrm{TiCl}_{4}$ constituents along with Lewis base (LB); normally referred as electron donor is the triggering factor for improving the stereoregularity of PP. LBs which are integrated part of catalyst system with directly bonding to the $\mathrm{MgCl}_{2}$ support are typically named 
as internal donor (ID) [11-16]. Besides this for generating iPP, another class of LB called external donor (ED) is added in most cases since some of weakly associated ID leach out during cocatalyst addition [17-21]. This ED not only balance the leached out ID but also helps in further enhancing stereo regularity of PP chains by the concurrent effect of poisoning non stereospecific site and activating isospecific one [22]. However, ID candidates have a higher impact on iPP since they intensely modify stereoregularity, regeoselectivity, activity and molecular weight distribution (MWD). As mentioned the IDs playing a key role in the ZN catalyzed propylene polymerization, therefore, the new electron donor development at present is one of the increasingly interest area for PP research.

The inherent complexity of heterogeneous ZN system along with distinctly rather complexities on ID and ED behavior on $\mathrm{MgCl}_{2}$ surface plus other features like hydrogen effect and poisoning makes it very challenging for understanding the fundamental behavior of the system. Since a few decades, the research work on $\mathrm{ZN}$ catalysts for iPP both in industry and in academia has been focused on how the structure of the IDs tailors the polymer properties like xylene solubility (XS), molecular weight (MW), and MWD.

\section{Isotactic polypropylene and Ziegler Natta catalysts with different generations}

Propylene being an asymmetric monomer; its different orientations both on stereo regularity and region regularity during polymerization lead to distinct chain configurations. Varying degree of regioselectivity and stereoselectivity in PP enables the resins ranging from amorphous to crystalline materials at room temperature leading to atactic, syndiotactic and isotactic microstructures (Fig. 1); though iPP which melts in the range $165-173{ }^{\circ} \mathrm{C}$ is by far the most relevant material in commercial level.

Initial characterization of atactic and isotacticity of PP was carried out by differential solubility methods by Natta et al. [23]. $n$-alkanes with increasing boiling points like $n$-heptane were particularly applied for measurement of crystalline fractions. However, in the use of $n$-heptane soluble fractions, atactic polymers were accompanied with low MW isotactic fractions too. Earlier atactic content in iPP is mainly determined by XS analysis where the dissolution of the polymer in xylene is at $135{ }^{\circ} \mathrm{C}$ followed by precipitation of amorphous fraction on cooling. Later sophisticated analytical tools like CRYSTEF was designed to serve this purpose. The more detailed information on PP tacticity was determined by NMR measurements which is covered in detail in the latter part of the review.

\section{First generation ( $1^{\text {st }}$ Gen) catalyst}

The commercial ZN catalyst called $1^{\text {st }}$ Gen catalysts involved $\delta-\mathrm{TiCl}_{3} \cdot 0.33 \mathrm{AlCl}_{3}+\mathrm{AlEt}_{2} \mathrm{Cl}$ applied for PP and showed low productivity of $0.8-1.2 \mathrm{kgPP} / \mathrm{gCat}$ and isotactic index (II) of $90-94 \%$ [24]. The mechanism of traditional ZN catalyst involves activation of $\mathrm{TiCl}_{4}$ by cocatalyst $\mathrm{AlEt}_{3}$. On the crystal surface of $\mathrm{TiCl}_{4}$, titanium atom surrounded by five chlorine atoms along with empty orbital to be filled. $\mathrm{AlEt}_{3}$ abstracts the chlorine from titanium center and chain initiation begins with alkene-metal formation. Further alkenemetal complex undergoes electron shuffling between $\mathrm{Ti}$ and $\mathrm{AlEt}_{3}$ and forms bond between ethyl group and methyl substituted carbon of propylene (Fig. 2).
Fig. 1 Representation of (a) Isotactic (b) Syndiotactic and (c) Atactic PP (a)<smiles>CCC[C@H](C)C[C@@H](C)C[C@H](C)C[C@H](C)C[C@H](C)C[C@H](C)C[C@@H](C)CC(C)C</smiles>

(b)<smiles>C=C(CCC)C[C@H](C)CC(=C)C[C@@H](C)CC(=C)C[C@@H](C)CC(=C)CC(C)C</smiles>

(c)<smiles>C=CC[C@@H](C)CC(=C)CC(=C)C[C@@H](C)C[C@H](C)C[C@@H](C)CC(=C)CC(C)C</smiles> 
Fig. 2 Mechanism of traditional $\mathrm{ZN}$ catalyst for propylene polymerization

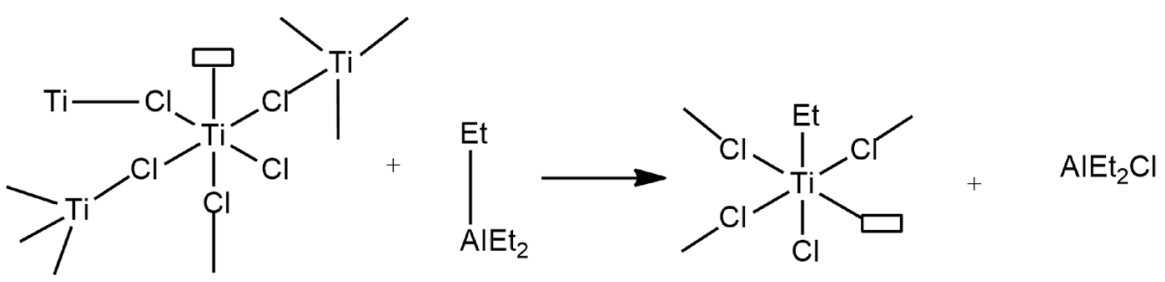<smiles>C=CC</smiles><smiles>CC1(C)[C@]23CC[C@]12C3(C)C</smiles><smiles></smiles>

PP manufacturers on early days required post treatment process for getting rid of atactic fractions and residues from transition metals and also chloride compounds.

\section{Second generation ( $2^{\text {nd }}$ Gen) catalyst}

In the early 1970s improvement in PP catalysts was manifested by Solvay which latter named as $2^{\text {nd }}$ Gen (Solvay) catalyst with the employment of DEAC cocatalyst. The reduction of $\mathrm{TiCl}_{4}$ with DEAC generates microstructure of $\mathrm{TiCl}_{3}$; with a spherical morphology, high surface area and narrow MWD. These catalysts resulted in tremendous improvement in activity of $10-15 \mathrm{kgPP} / \mathrm{gCat}$ and stereospecificity in the increased range of 2-3\% (II: 96-98) [24, 25].

\section{Third generation ( $3^{\text {rd }}$ Gen) catalyst}

In the conventional $1^{\text {st }}$ Gen ZN catalyst and also Solvay catalyst, Ti residing in the interior are inactive for monomer and cocatalyst. The hidden titanium does not transform into active species during polymerization, subsequently only less amount of titanium centers triggers the polymer production. Efforts in developing supported catalysts started very early in the 60 's by utilizing conventional supports with surface functional groups able to anchor chemically on metal ions. Inorganic compounds from different classes were tested as supports. Magnesium compounds like $\mathrm{MgO}, \mathrm{Mg}(\mathrm{OH})_{2}, \mathrm{Mg}(\mathrm{OR})_{2}$ have been used, however anhydrous $\mathrm{MgCl}_{2}$ served to be attractive for $\mathrm{TiCl}_{4}$ due to their inherent similarities like radii, bond lengths, lattices (radius; $\mathrm{Mg}^{2+}\left(0.65 \mathrm{~A}^{0}\right)$ vs $\mathrm{Ti}^{4+}(0.68$ $\left.\mathrm{A}^{0}\right)$, bond length ( $\mathrm{Mg}-\mathrm{Cl}: 2.57 \mathrm{~A}^{0}$ vs Ti-Cl: $\left.2.51 \mathrm{~A}^{0}\right)$, lattice: isomorphic) [26]. In $1968 \mathrm{MgCl}_{2}$ supported $\mathrm{TiCl}_{4}$ catalyst later named as $3^{\text {rd }}$ Gen catalyst was developed
$[27,28]$. Due to the above mentioned features, $\mathrm{MgCl}_{2}$ enforces the titanium centres to bind on its surface, enabling in stabilization of the transition metal leading to the subsequent chemical reactions on the titanium site. These supported catalysts improved the productivity of PP (>10 kg/gcat), however they brought down the stereospecificity of PP (II $<50 \%)$. Activated $\mathrm{MgCl}_{2}(\delta$ $\mathrm{MgCl}_{2}$ ) is typically applied and found to be beneficial for supporting $\mathrm{TiCl}_{4}$ [29-34]. Activation of $\mathrm{MgCl}_{2}$ was generally carried out by different methods which include milling of $\mathrm{MgCl}_{2}, \mathrm{MgCl}_{2}$ alcohol adducts, and chlorination of alkyl or alkoxy magnesium compounds.

$\mathrm{MgCl}_{2} \cdot \mathrm{nEtOH}+\mathrm{xsMCl}_{4} \rightarrow \mathrm{MgCl}_{2}+\mathrm{n}-\mathrm{EtOMCl}_{3}+\mathrm{n}-\mathrm{HCl}$

$\mathrm{M}=\mathrm{Si}, \mathrm{Sn}, \mathrm{Ti} ; \mathrm{Et}=\mathrm{C}_{2} \mathrm{H}_{5}$

$\mathrm{MgR}_{2}+2 \mathrm{SiCl}_{4} \rightarrow \mathrm{MgCl}_{2}+2 \mathrm{RSiCl}_{3}$

$\mathrm{Mg}(\mathrm{OEt})_{2}+2 \mathrm{MCl}_{4} \rightarrow \mathrm{MgCl}_{2}+2 \mathrm{EtOMCl}_{3}$

A disordered structure is often present in the activated form, which is mainly due to the translation and rotation of $\mathrm{Cl}-\mathrm{Mg}-\mathrm{Cl}$ layers with respect to one another. In the activated $\mathrm{MgCl}_{2}$, the most stable layer is 001 basal plane derived by the cleavage of $\mathrm{MgCl}_{2}$ stacking and is coordinately saturated [35]. However, it has two unsaturated lateral planes (110 and 104 planes) with four and five fold coordinative unsaturated $\mathrm{Mg}^{2+}$ ions respectively.

However, the problem of lowering stereospecificity was later resolved by the addition of a third component, ID in $3^{\text {rd }}$ Gen supported titanium catalysts, which dramatically improved isotacticity. Monoesters typically ethyl benzoate (EB) [36-38] were initially more successfully employed ID in particular combination with ED (p-methyl toluate or methyl anisate) added during polymerization process. 
The function of ED is to maintain the stereo regularity of the sites where ID leaches out with cocatalyst addition. $\mathrm{MgCl}_{2}$-supported donor modified catalyst is later treated as the parent for the next few generations of catalysts.

\section{Fourth generation ( $4^{\text {th }}$ Gen) catalyst}

In 1981-1982 a new supported catalyst with bifunctional phthalate ID and organosilicon compound as ED was developed by Mitsui Petrochemicals with the use of TEAL as cocatalyst as being less reactive to organosilicon compound [39]. This catalyst increased the activity up to $50 \mathrm{~kg} / \mathrm{g}$.cat and isotacticity reached $98 \%$. This methodology was further improved to increase the activity up to $100 \mathrm{~kg} / \mathrm{g}$.cat. This $4^{\text {th }}$ Gen catalysts with certain breadth on MWD with polydispersity index (PDI): 4-7 have good performance on temperature profile and also on $\mathrm{H}_{2}$ sensitivity. Increase in polymerization temperature, and also the $\mathrm{H}_{2}$ concentration improves activity with minimal effect on II relative to $3^{\text {rd }}$ Gen catalyst.

\section{Fifth generation ( $\left.5^{\text {th }} \mathrm{Gen}\right)$ catalyst}

Researchers recognized donor molecules as the driving vehicles for improving isotacticity and activity of PP catalysts; and more focus then directed on varying the ID and ED structures for customizing catalyst performance towards specific needs. In 1981, Montedison researchers developed supported ZN system with the use of 1,3-diethers as ID:
9,9'-bis(methoxymethyl)fluorene(BMMF), 2,2'-diisobutyl1,3-dimethoxypropene (DIBDMP) (Fig. 4) [40-42]. With $5^{\text {th }}$ Gen ZN catalyst, very high activities and xylene insoluble (XI \%) 95-99 were achieved. These catalysts exhibit high hydrogen sensitivity (20 times the sensitivity of $4^{\text {th }}$ Gen catalyst) without the aid of ED. These features were directed in bringing narrow MWD (PDI 3-5) [43]. Applications of this type of catalysts include injection molding, fibers and very high melt flow rates to the formed polymers.

\section{Sixth generation $\left(6^{\text {th }}\right.$ Gen $)$ catalyst}

Basell developed $6^{\text {th }}$ Gen supported ZN catalyst with the use of succinate ID (Fig. 3). These type of catalysts broaden MWD (PDI: 5-15) [44]. By then responsibility of different families of donors in bringing the stereospecificity in the catalysts and improvements in the catalyst activity, hydrogen response, MWD etc. were well understood. These generations of catalysts are summarized in the Table 1.

\section{Different classes of internal donors}

The use of electron donor (combination of ID and ED) played significant role in ensuring the catalyst with satisfactory activity and stereospecificity. In general, the requisite for a complete supported $\mathrm{ZN}$ catalyst for iPP synthesis is the involvement of ID (added during catalyst preparation)
Fig. 3 Different classes of IDs for $\mathrm{ZN}$ catalysts, Two different co-ordination modes of $\mathrm{AIEt}_{3}$ with DIBP<smiles>[R]OC(=O)c1ccccc1</smiles>

Benzoate ID<smiles>[R]OC(=O)c1ccccc1C(=O)O[R]</smiles>

Phthalate ID<smiles>[R]OCC([R])([R])CO[R]</smiles>

Diether ID<smiles>[R]OC(=O)C([R])([R])C([R])([R])C(=O)O[R]</smiles>

Succinate ID<smiles>CC(C)CC(=O)c1ccccc1C(=O)CC(C)C(C)C</smiles> 
Table 1 Different generations of ZN catalysts

\begin{tabular}{|c|c|c|c|c|}
\hline Generation & Catalyst composition & $\begin{array}{l}\text { Productivity } \\
\text { (kg PP/g cat) }\end{array}$ & $\begin{array}{l}\text { II } \\
(\%)\end{array}$ & Remarks \\
\hline $1^{\text {st }}$ & $\mathrm{TiCl}_{4}-0.33 \mathrm{AlCl}_{3}$ & $0.8-1.2$ & $90-94$ & Major fraction of atactic polymer \\
\hline $2^{\text {nd }}$ & $\mathrm{TiCl}_{4}+\mathrm{DEAC}$ (Solvay catalyst) & $10-15$ & $96-98$ & $\begin{array}{l}\text { Spherical morphology, greater } \\
\text { stereochemical control }\end{array}$ \\
\hline \multirow[t]{2}{*}{$3^{\text {rd }}$} & $\mathrm{MgCl}_{2} / \mathrm{TiCl}_{4}+\mathrm{AlR}_{3}$ & $>10$ & $<50$ & Improved activity, very low stereo control \\
\hline & $\mathrm{MgCl}_{2} / \mathrm{TiCl}_{4} /$ Benzoate $/ \mathrm{AlR}_{3}$ & $15-30$ & $95-97$ & $\begin{array}{c}\text { Improved stereo control, low } \mathrm{H}_{2} \text { response, } \\
\text { broad MWD }\end{array}$ \\
\hline $4^{\text {th }}$ & $\begin{array}{l}\mathrm{MgCl}_{2} / \mathrm{TiCl}_{4} / \text { Phthalate }+ \\
\mathrm{AlR}_{3} / \text { Silane }\end{array}$ & $50-100$ & $\begin{array}{l}\text { up to } \\
98\end{array}$ & $\begin{array}{l}\text { Spherical catalyst with controlled porosity, } \\
\text { medium-high stereo control, medium } \mathrm{H}_{2} \\
\text { response, medium MWD }\end{array}$ \\
\hline $5^{\text {th }}$ & $\begin{array}{l}\mathrm{MgCl}_{2} / \mathrm{TiCl}_{4} / \text { Diether } \\
+\mathrm{AlR}_{3} / \text { Silane (opt.) }\end{array}$ & $70-130$ & $95-99$ & $\begin{array}{c}\text { Same as } 4^{\text {th }} \text { generation butvery high } \\
\text { activity, narrow MWD, excellent } \mathrm{H}_{2} \\
\text { response }\end{array}$ \\
\hline $6^{\text {th }}$ & $\begin{array}{c}\mathrm{MgCl}_{2} / \mathrm{TiCl}_{4} / \text { Succinate }+ \\
\mathrm{AlR}_{3} / \text { Silane }\end{array}$ & $40-70$ & $95-99$ & Same as $5^{\text {th }}$ generation but broad MWD \\
\hline
\end{tabular}

and ED (added during polymerization) [45-47]. The characterization of this heterogeneous catalyst involving LB is long lasting challenge, interrupted with both experimental and theoretical studies, but conclusive answers have not been attained yet. The main group of IDs are benzoate, phthalate, diether and succinate type (Fig. 3).

\section{Benzoates internal donors}

Monoester of aromatic carboxylic acid like ethyl benzoate (EB) (Fig. 4) are more commonly used ID among this class. Busico et al. [48], Yunxiang and Lin [49] and Zhang [50] used different substituted EB in ZN catalyst for propylene polymerization and found that increasing the ester length can improve the stereo specificity. The kinetic behavior of $\mathrm{MgCl}_{2} / \mathrm{TiCl}_{4} / \mathrm{EB}$ in the presence of activator $\mathrm{AlEt}_{3}$ for propene slurry polymerization was studied by Keii et al. [51]. The rate of polymerization as a function of polymerization temperature showed maximum which is in alignment with the rate law. By employing the inhibition method with carbon monoxide, the number of active centers of catalyst were estimated in gas phase propene polymerization. The performance of ethyl p-toluate (Fig. 4) was relatively better, however the removal of atactic polymer was still challenging.

\section{Phthalate internal donors}

Phthalate esters especially diisobutyl phthalate (DIBP) and di-n-butylphthalate (DNBP) (Fig. 4) are most widely used IDs [52]. Phthalate ID generally gives PP with medium MWD and high activity (Table 2). These catalysts are sensitive to ED as some amount of ID could leach out during the addition of cocatalyst. The phthalate IDs enabled to function on controlling the amount and distribution of $\mathrm{TiCl}_{4}$ [52]. Phthalate-based ZN catalysts are potentially harmful to the environment and, hence, regulated by $\mathrm{REACH}$. In recent years, many researches focus on discovery of more potent electron donors for the $6^{\text {th }}$ Gen ZN PP catalysts. In spite of the fact that the phthalate-based catalysts produce PP with far lower phthalate content below the $0.3 \mathrm{wt} \%$ concentration limit in the REACH Regulation, a totally phthalatefree solution is highly motivated and becomes a competitive advantage.

\section{Active centres of phthalate catalysts}

Among phthalate ID, DIBP (Fig. 4) is the most studied candidate by the Researchers. Phthalate IDs have affinity on both coordinately unsaturated 110 and 104 planes of $\delta \mathrm{MgCl}_{2}$ [53]. Fan et al. used kinetic study for understanding the different active centres of DIBP/ $\mathrm{MgCl}_{2} / \mathrm{TiCl}_{4}$-TEA in presence of EDdicyclopentyldimethoxysilane (DCPDMS) [54]. Their study typified that predominant role of phthalate is to change the active center distributions $\left(\mathrm{C}^{*}{ }_{\mathrm{i}}\right.$ (isotactic), $\mathrm{C}^{*}{ }_{\mathrm{mi}}$ (medium isotactic) and $\mathrm{C}^{*}{ }_{\mathrm{a}}$ (atactic)) of PP catalyst, however the reactivity of activity centres lie in nearly unchanged fashion. This was illustrated by the introduction of phthalate donor which enhances $\mathrm{C}^{*}$ to $32 \%$ relative to $22 \%$ observed in blank catalyst. The addition of DCPDMS used in the case study caused significant increase of $\mathrm{C}^{*} \mathrm{C}_{\mathrm{i}}^{*},\left(\mathrm{C}^{*}=\mathrm{C}^{*}{ }_{\mathrm{I}}+\mathrm{C}^{*}{ }_{\mathrm{mi}}+\mathrm{C}^{*}{ }_{\mathrm{a}}\right)$ up to $54 \%$ and also reactivity of $\mathrm{C}^{*}$. These two combined kinetic effects overwhelming dominance on iPP production. These results are in accordance with the literature reports where addition of $\mathrm{ED}$ enhances the isotacticity of PP in Phthalate/ $\mathrm{MgCl}_{2} / \mathrm{TiCl}_{4}$ system [55]. 


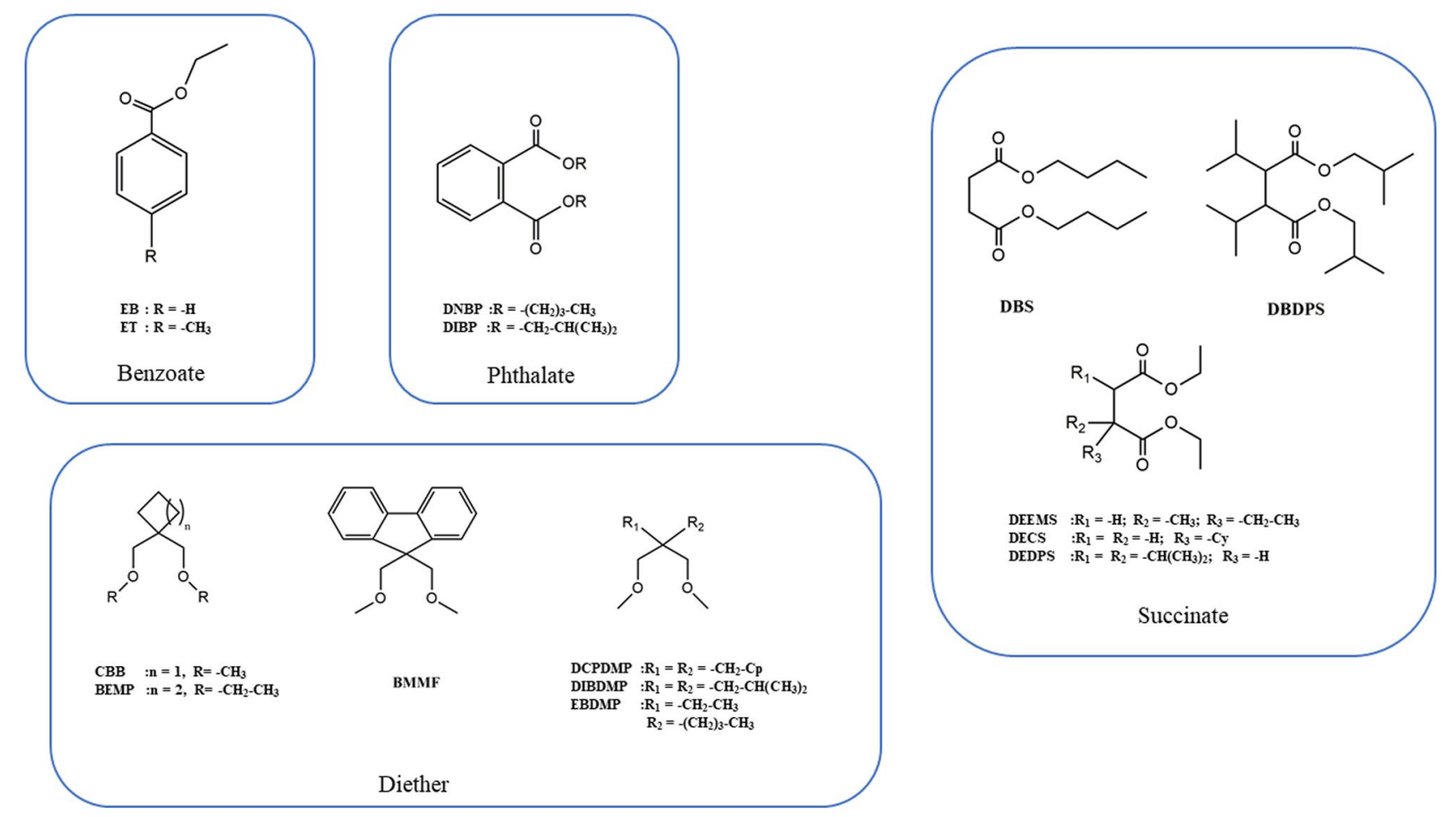

Fig. 4 Derivatives of benzoate, phthalate, diether and succinate IDs applied on ZN catalysts

Research groups at Boreskov Institute of Catalysis studied the influence of DNBP on active centre amounts and rate constants of propagation states for stereo specific and non-stereospecific centres in $\mathrm{DNBP} / \mathrm{MgCl}_{2} / \mathrm{TiCl}_{4}$ system [56]. It was noted that upon addition of DNBP for stereospecific centres, rate constant of growth $\left(K_{g}\right)$ remain unchanged, however these values dramatically decreased for non-stereospecific centres. It is more reasonable to explain that ID blocks 110 face of $\mathrm{MgCl}_{2}$ surface where the adsorbed $\mathrm{TiCl}_{4}$ has highly reactive low stereospecific centres or non-stereospecific centres. It was also determined that fractions of stereospecific centres improved by a factor 2 while fraction of non-stereospecific centres decrease very slightly. This was justified by decrease in $K_{g}$ for non-stereospecific centres and low stereospecific centres.

\section{Structure analysis of phthalate catalysts}

Two main tools employed by Researchers for DIBP catalyst structural analysis are FTIR and NMR spectroscopy [57-59]. In FTIR spectroscopy, three interesting bands studied are $>\mathrm{CO}$ stretching band and $\mathrm{C}-\mathrm{O}-\mathrm{C}$ symmetric and asymmetric stretching frequencies [60]. The shifting of $-\mathrm{C}=\mathrm{O}$ stretching frequency from $1728 \mathrm{~cm}^{-1}$ to a broad peak at $1687 \mathrm{~cm}^{-1}$ up on coordination with $\mathrm{MgCl}_{2}$ was observed. The broadness of peak in the catalyst is an evidence for the existence of various complexes of DIBP with $\mathrm{MgCl}_{2}$. FTIR also gave the indication of other side products formed on catalyst system, like the presence of three peaks $1758,1832,1861 \mathrm{~cm}^{-1}$ indicating the existence of phthaloyl chloride at higher temperature. ${ }^{1} \mathrm{H}$ and ${ }^{13} \mathrm{C}\left\{{ }^{1} \mathrm{H}\right\} \mathrm{NMR}$ along with $2 \mathrm{D}{ }^{1} \mathrm{H}-{ }^{1} \mathrm{H}$ and ${ }^{13} \mathrm{C}$ - ${ }^{1} \mathrm{H}$ correlation spectroscopy of DIBP catalyst revealed the existence of other two phthalate esters as side products along with DIBP [60]. Kissin et al. [61] utilized both IR and ${ }^{1} \mathrm{H}$ and ${ }^{13} \mathrm{C}$ NMR spectroscopy for analyzing the interactive behavior of DIBP with $\mathrm{TiCl}_{4} / \mathrm{MgCl}_{2}$ in the presence of cocatalyst. $\mathrm{AlEt}_{3}$ and silyl ether $\left(\mathrm{CyMeSi}(\mathrm{OMe})_{2}\right.$. They illustrated the formation of different species on interaction of DIBP with $\mathrm{TiCl}_{4} / \mathrm{MgCl}_{2}: 1$ ) DIBP- $\mathrm{MgCl}_{2}$ complexes (dominant species); 2) $\mathrm{TiCl}_{4}$-DIBP complex; 3) physisorbed phthaloyl chloride (formed by the reaction of DIBP with $\mathrm{TiCl}_{4}$ ); 4) several complexes of phthaloyl chloride with $\mathrm{TiCl}_{4}$.

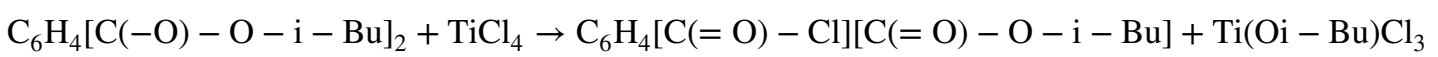

$\mathrm{C}_{6} \mathrm{H}_{4}[\mathrm{C}(=\mathrm{O})-\mathrm{Cl}][\mathrm{C}(=\mathrm{O})-\mathrm{O}-\mathrm{i}-\mathrm{Bu}]+\mathrm{TiCl}_{4} \rightarrow \mathrm{C}_{6} \mathrm{H}_{4}[\mathrm{C}(=\mathrm{O})-\mathrm{Cl}]_{2}+\mathrm{Ti}(\mathrm{Oi}-\mathrm{Bu}) \mathrm{Cl}_{3}$ 
Table 2 Comparison of properties of PP obtained with the aid of different IDs

\begin{tabular}{ccccc}
\hline & Benzoate ID & Phthalate ID & Diether ID & Succinate ID \\
\hline $\begin{array}{c}\text { Productivity } \\
\left(10^{3} \mathrm{Kg} \mathrm{PP} / \mathrm{g} \text { of Ti) }\right.\end{array}$ & $0.5-0.8$ & $1-2$ & $>2$ & $1-2$ \\
$\begin{array}{c}\text { XS } \\
(\text { wt } \%)\end{array}$ & $3-5$ & $1-5$ & $2-5$ & $1-5$ \\
PDI & $6-9$ & $6-8$ & $4-6$ & $>8$ \\
\hline
\end{tabular}

With the above mentioned analytical tools they figured out that when these complex species reacted with $\mathrm{AlEt}_{3}$ in presence of $\mathrm{CyMeSi}(\mathrm{OMe})_{2}$, all carbonyl groups which were adsorbed reacts strongly with $\mathrm{AlEt}_{3}$ leading to the complete removal of all phthaloyl chloride and significant reduction of $\mathrm{DIBP} / \mathrm{TiCl}_{4}$ and $\mathrm{DIBP} / \mathrm{MgCl}_{2}$ complexes. The order of reactivity was found to be physisorbed phthaloyl chloride $>$ phtholyl chloride/ $\mathrm{MgCl}_{2}$ complexes $>\mathrm{DIBP} / \mathrm{MgCl}_{2}$ complexes $\sim \mathrm{DIBP} / \mathrm{TiCl}_{4}$ complexes. The results illustrated by Kissin et al. [61] is in quite agreement with other literature data [62]. They also studied with the use of NMR analytical tool, the interactive behavior of ID with cocatalyst by preparing model system DIBP-AlEt ${ }_{3}$ (Fig. 3). Three distinctive doublets in the range from 3.98-4.85 ppm corresponding to $\alpha-\mathrm{CH}_{2}$ group were observed; justified all the esters formed complexes with $\mathrm{AlEt}_{3}$ while in free ester $\alpha-\mathrm{CH}_{2}$ groups resonate as multiplet in the range $4.34-4.36 \mathrm{ppm}$ (Fig. 3).

Further FTIR tool was also applied for understanding the quality of phthalate based ZN catalysts formed by over activation/under activation/contamination with moisture or hydroxyl groups; and thereby provide fairly good insights on catalytic performance [63] For example with increased activation temperature $\mathrm{CO}$ bands at $1700-1685 \mathrm{~cm}^{-1}$ becomes sharper. These bands were found to be weak for properly activated and also under activated catalysts. For the under activated catalysts
$\mathrm{TiCl}_{4}$ complexed with donor was found to observe, which was manifested by the presence of $\mathrm{CO}$ absorption maximum at $1650-1640 \mathrm{~cm}^{-1}$ being associated with additional bands at $435-430 \mathrm{~cm}^{-1}$ The insufficiently dried raw materials generate catalysts contaminated with hydroxyl and water impurities, which shows absorptions at $3550-3520 \mathrm{~cm}^{-1}$ for hydroxyl impurities and $3370 \mathrm{~cm}^{-1}$ and $1612 \mathrm{~cm}^{-1}$ for water impurities. FTIR spectrum was also used as a tool for understanding the complex pattern on the interaction of $\mathrm{TiCl}_{4}$ with $\mathrm{EB}$. Martin et al. used FTIR tool for analyzing the coordination behavior of $\mathrm{TiCl}_{4}$ with $\mathrm{EB}$ and elucidated the occurrence of three different complexes $\left(\mathrm{TiCl}_{4} \mathrm{~EB}\right)_{2}$, $\left(\mathrm{TiCl}_{4}\right)_{2} \mathrm{~EB}$ and $\mathrm{TiCl}_{4}(\mathrm{~EB})_{2}$ [64] from different modes of shifts in $\mathrm{CO}$ vibrations. For $\left(\mathrm{TiCl}_{4} \mathrm{~EB}\right)_{2}$ the most significant strong CO bands lie at $1560-1600 \mathrm{~cm}^{-1}$ and for $\left(\mathrm{TiCl}_{4}\right)_{2} \mathrm{~EB}$ a strong band at $500 \mathrm{~cm}^{-1}$ was observed which is primarily due to excess $\mathrm{TiCl}_{4}$ species. Piovano et al. [65] have carried out the insitu demonstration of $\mathrm{EB}$ absorption on $\mathrm{MgCl}_{2}$ supported $\mathrm{ZN}$ catalyst by FTIR spectroscopy and with DFT methods demonstrated the existence of $\mathrm{TiCl}_{4}(\mathrm{~EB})$ and $\mathrm{TiCl}_{4}(\mathrm{~EB})_{2}$ complexes on different catalytically relevant $\mathrm{MgCl}_{2}$ surface.

\section{Diether internal donors}

With the development of 1,3-diether (Fig. 3) based PP catalyst, this ID class have emerged as unique characteristics

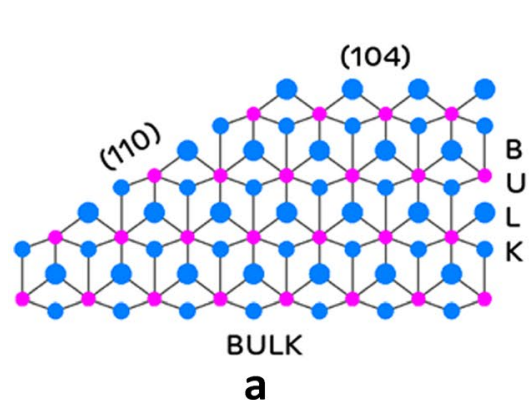

a

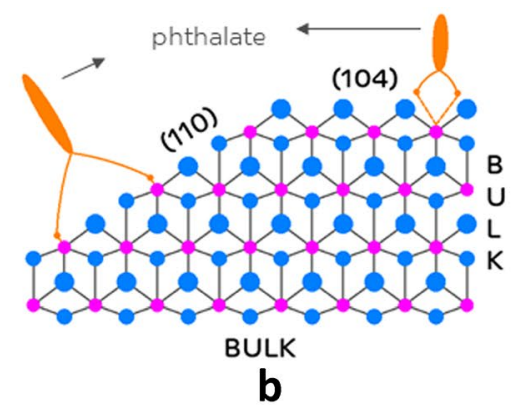

b
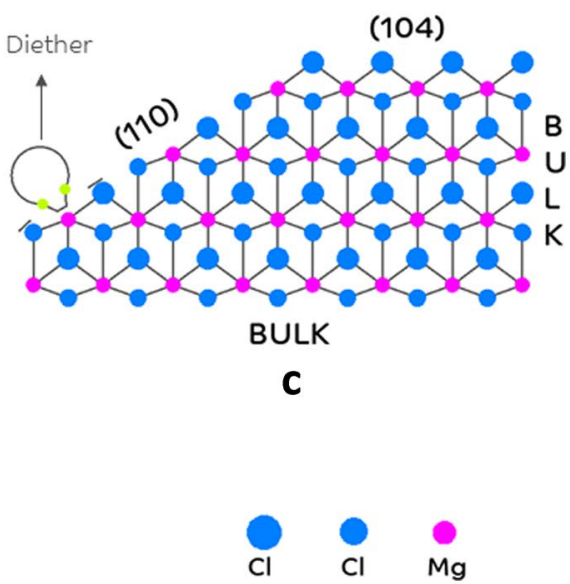

Fig. 5 Representation of (a) 104 and 110planes of $\mathrm{MgCl}_{2}$ (b) Anchoring mode of phthalate ID on $\mathrm{MgCl}_{2}$ surface (c) Anchoring mode of diether ID on $\mathrm{MgCl}_{2}$ surface 
as these donors give PP with narrow MWD, high hydrogen response and high isotacticity (Table 2). The $\mathrm{ZN}$ catalyst with 1,3-diethers are in great demand for industrial purpose due to their improved chemical stability toward $\mathrm{TiCl}_{4}, \mathrm{AlEt}_{3}$, $\mathrm{Ti}-\mathrm{C}$ and $\mathrm{Ti}-\mathrm{H}$ bonds, and also with the consideration that cocatalyst cannot extract these donor molecules from the solid component of the catalyst. These catalysts exhibit good stereospecificity and also good hydrogen response, making them more significant in terms of polymer grades. The various literatures and patents covering the functions carried out by these donors for iPP have been reported [66-69]. Studies have been devoted to the mechanism by which these donors interact with other components in the catalyst and also from theoretical point, several models have been proposed for the structure of isospecific and aspecific centers with these donors [70]. PP generated by this catalyst have good physical, organoleptic and better transparency with great appeal for applications like fiber, health care products and packaging materials. 2,2-disubstituted-1,3-dimethoxypropane and BMMF (Fig. 4) are the most widely studied candidates among diether class [71, 72]. Substituents on the diether moiety also played a vital role in improving the stereoselectivity and catalyst activity, which will be conferring in the coming session. Preferred mode of coordination of 1,3-diether compounds on $\mathrm{MgCl}_{2}$ surface is chelate mode (Fig. 5), which is very effective under the action of $\mathrm{AlEt}_{3}$ and thus, these molecules not leaching out during polymerization and are relatively insignificant for ED sensitivity.

\section{Sterically hindered diethers}

Several research works were attempted to deduce the correlation between sterically hindered groups of diethers and polymerization performance since two to three decades. The active site's steric environment is regulated by ethereal moiety involving oxygen atom or methyl group or by bulky groups exist on the central carbon atom of diether. Some studies described that base is responsible to convert aspecific centres into isospecific ones by introducing steric environment; the base can adopt two modes of coordination: 1) bridge between $\mathrm{Mg}$ and $\mathrm{Ti}, 2)$ bond to $\mathrm{Mg}$ atom adjacent to active Ti centre [73]. The second mode of coordination is more supportive and is in good agreement with spectroscopic studies on catalyst component with electron donors [74-76]. For example direct coordination of Ti center with base was excluded by IR [77-79] and weakening of $\mathrm{Ti}-\mathrm{Cl}$ bond suggesting electron donor is coordinated to $\mathrm{Mg}$ atom adjacent to active Ti center. The adsorption of Ti-Cl absorptions of inTiCl ${ }_{4}$ at 386 and $495 \mathrm{~cm}^{-1}$ found to be disappear in the spectrum of $\mathrm{MgCl}_{2} / \mathrm{TiCl}_{4}$ supported catalyst, and a new absorption found to appear at $450 \mathrm{~cm}^{-1}$ that shifts to $420 \mathrm{~cm}^{-1}$ in $\mathrm{MgCl}_{2}-\mathrm{TiCl}_{4}$-diether catalyst [80]. Morini et al. underwent the early study on 1,3-diether by using dialkyl substituted propane diethers with different sterically hindered groups (DIBDMP, DCPDMP and EBDMP) (Fig. 4) on $\mathrm{MgCl}_{2}$ supported $\mathrm{ZN}$ catalysts [80]. Their work enabled in significant progress in understanding the correlation between ID and ED from the catalyst analysis and stereo chemistry of polymerization. DIBDMP and DCPDMP bearing branched and bulkier groups performed good behavior on propylene polymerization; however, linear and less bulky dietherEBDMP was shown lower performance while considering catalyst activity and stereospecificity.

More details on these three catalysts with respect to donor free and traditional phthalate catalysts with respect to their mechanistic performance and polymer tacticity would be discussed in the below sections. Researchers have also demonstrated the influence of change in diether content on catalyst performance. A detailed study was performed with two different catalysts (BMMF) and (CBB) (Fig. 4) with variable diether $/ \mathrm{Mg}$ ratio [27]. Irrespective of donor with the increase of diether/Mg ratio, diether content increases while $\mathrm{Mg}$ amount decreases, however the change is more drastic for the catalyst with BMMF with respect to CBB [diether/Mg ratio as $20 / 100$, the decrease in $\mathrm{Ti}$ content by $\sim 4 \%$ (BMMF), 2\% (CBB) and increase in diether content by $49.17 \%$ (BMMF), $16 \%$ (CBB)]. BMMF with its sufficient bulkiness, strong electron donating group would bind strongly with $\mathrm{Mg}$ adjacent to the active site while comparing with $\mathrm{CBB}$ having poor steric hindrance, strong tension and relatively poor electron donating ability. When BMMF/ $\mathrm{Mg}$ ratio is below 20/100, the adsorption occurs on poorly isospecific sites where Ti content decreases rapidly and BMMF content increases greatly. With further increase in $\mathrm{BMMF} / \mathrm{Ti}$ ratio, BMMF has to compete with highly stable and highly isospecific active site (which was in kinetic equilibrium with poorly isospecific site), where BMMF found tedious to replace $\mathrm{Ti}$ in the site leading to smooth composition change in the catalyst.

\section{Diether versus phthalate classes}

While considering the literature reports, largely studies were focused on development of new structurally diversified diethers (Fig. 4) and their comparison with existing phthalate IDs on supported ZN catalyst system with respect to their PP isotacticity, regioselectivity and ID/ $\mathrm{MgCl}_{2}$ ratio on polymer properties with attempt to lighten the structural modification of IDs.

PP isotacticity Morini et al. [80] for better characterization of polymers obtained from three different catalysts of structurally different diethers (DIBDMP, DCPDMP, EBDMP) (Fig. 4), TREF analysis was performed in conjunction with ${ }^{13} \mathrm{C}$ NMR stereo sequence distribution of different fractions. TREF elution profiles of PPs are generally considered as tacticity profiles, for example 
four fractions with different elution temperatures $\left(\mathrm{T}_{\mathrm{el}}\right)$ obtained in their study; 1$)$ atactic $\left.\left(\mathrm{T}_{\mathrm{el}}<25^{\circ} \mathrm{C}\right), 2\right)$ stereo blocks $\left.\left(\mathrm{T}_{\mathrm{el}}=26-99{ }^{\circ} \mathrm{C}, \mathrm{mmmm}<90 \%\right), 3\right)$ mainly isotactic $\left.\left(100-108{ }^{\circ} \mathrm{C}, \mathrm{mmmm}=90-95 \%\right), 4\right)$ highly isotactic ( $\mathrm{T}_{\mathrm{el}}>108^{\circ} \mathrm{C}$ ). In DIBDMP and DCPDMP catalysts, polymers mainly comprise of highly isotactic fraction 4 . The fraction 2 represented by stereo blocks can be reduced by donor functioning in two ways a) saturating $\mathrm{Mg}$ atoms coordination vacancy adjacent to isospecific dinuclear $\mathrm{Ti}$ adduct $\mathrm{b}$ ) saturating the vacancy of inactive $\mathrm{Ti}$ of $\mathrm{Ti}_{2} \mathrm{Cl}_{6}$ dimer. In DIBDMP, DCPDMP and phthalate/silane catalyst systems, the increase in isotactic productivity and high percent of highly isotactic fraction 4 can be illustrated by increase in dimeric $\mathrm{Ti}$ species or generation of new isospecific Ti species, and decreased atactic fractions is caused by selective complexation of tetra coordinated magnesium atom. In comparison to donor free catalyst, EBDMP showed higher isotactic index around 92\%. In EBDMP, 53\% polymer represents mainly isotactic fraction 3. Both EBDMP catalyst and donor free catalyst showed similar features in certain cases: $4^{\text {th }}$ fraction is completely absent, fraction 3 of both catalysts have similar elution curves and melting point of both polymers are same. Authors depicted two particular reason for the absence of fraction 4 in EBDMP catalyst a) stability constant of chelate complex on $\mathrm{Mg}$ atom is not sufficiently high b) EBDMP with its linearity and less bulky substituents not efficient enough to coordinate on $\mathrm{Mg}$ atom adjacent to active Ti center for bringing highly isospecific centers. This explanation was also supported by molecular modelling calculation which have shown that Ti do not have right chiral center for highly isotactic fractions due to the lack of much bulky hydrocarbon substituents [68].

Regioselectivity and hydrogen response The influence of hydrogen concentration on MW of polymer is dependent on catalyst system. Diether type catalysts due to high hydrogen sensitivity, MW control can be triggered by relatively little hydrogen. The chain transfer with hydrogen after the occasional secondary 2,1 insertion rather than usual 1,2 insertion is responsible for this effect. Chadwick et al. [81] did analysis for determining the regioselectivites of two different catalyst systems- $\mathrm{MgCl}_{2} / \mathrm{TiCl}_{4} / \mathrm{DIBP}$ and $\mathrm{MgCl}_{2} / \mathrm{TiCl}_{4} /$ diether. The 2,1-inserted units is more pronounced with significant level in the isotactic and weakly atactic fractions in diether type $(0.15 \%$ isotactic, $0.5 \%$ atactic) while comparing with phthalate type (2,1-inserted units: $0.08 \%$ (weakly tactic)). This result can be attributed to the fact that high hydrogen response of the diether type catalyst resulted in uniform distribution of 2,1-inserted units throughout the polymer whether having isotactic or weakly tactic fractions. This picturized that there exists no base rule for highly isospecific diether type catalysts to be completely regiospecific. The low content of 2,1-inserted units in isotactic fractions of phthalate type catalysts revealed that low hydrogen response of this catalyst. The occurrence of some highly regiospecific active sites in this type of catalysts is responsible for having fractions with high MW and broad MWD. The study revealed fundamental implications on the effect of catalyst regioselectivity on PP MWD; the catalyst having the active species with very high regioselectivity would result in low hydrogen response and thus broad MWD and the active sites with lower regioselectivity at high hydrogen concentration results in low MW fraction.

Cross combination study Saachi et al. investigated cross combination study by treating three diethers: DIBDMP, DCPDMP, EBDMP as EDs and DIBP (Fig. 4) as ID to understand the mechanism of ID-ED correlations [70]. The results found cleared that similar isospecific centers are generated when these diethers are used as ID or replaces DIBP by adding diether as ED during polymerization. However, resulting in lower yields, which can be explained by the occurrence of some poisoning effect on both aspecific and isospecific sites when diethers are added as ED. A general conclusion of reciprocal behavior of ID and ED on the catalyst system was concluded since the similar effect was also noted when the concentration of ED is increased beyond certain values in $\mathrm{MgCl}_{2} /$ phthalate/ $/ \mathrm{TiCl}_{4}-\mathrm{AlEt}_{3} /$ silane system and rationalized a reaction model with the interactions among the catalyst system components.

$$
\begin{aligned}
& \text { Cat.ID }+\mathrm{AIEt}_{3}=\mathrm{Cat}-[]+\mathrm{AIEt}_{3} \cdot \mathrm{ID} \\
& \mathrm{ED}+\mathrm{AIEt}_{3}=\mathrm{AIEt}_{3} \cdot \mathrm{ED}
\end{aligned}
$$

Cat -[]$+\mathrm{ED}=$ Cat.ED

$\mathrm{Cat}-[]+\mathrm{AIEt}_{3} \cdot \mathrm{ED}=\mathrm{Cat}_{\text {.AIEt }} \cdot \mathrm{ED}$

Where Cat-[ ] is a free site.

Internal donor $/ \mathrm{MgCl}_{2}$ ratio $\mathrm{A}$ detailed study was performed with BMMF and CBB (Fig. 4) catalysts with variable diether/Mg ratio [27]. Irrespective of donor with the increase of diether/Mg ratio, diether content increases while Mg amount decreases, however the change is more drastic for the catalyst with BMMF with respect to CBB [diether/Mg ratio as 20/100, the decrease in Ti content by $\sim 4 \%$ (BMMF), 2\% (CBB) and increase in diether content by $49.17 \%$ (BMMF), 16\% (CBB)]. BMMF with its sufficient bulkiness, strong electron donating group would bind strongly with $\mathrm{Mg}$ adjacent to the active site while comparing with CBB having poor steric hindrance, strong tension and relatively poor electron donating ability. When BMMF/Mg ratio is below 20/100, the adsorption occurs on poorly isospecific Type 1 active (illustrated in coordination 
mode section) where content of Ti decreases rapidly and BMMF content increases greatly. With further increase in BMMF/Ti ratio, BMMF has to compete with highly stable and highly isospecific type II active site (which was in kinetic equilibrium with Type 1 site), where BMMF is challenging to replace $\mathrm{Ti}$ in the site leading to smooth composition change in the catalyst.

Competitive behavior of diether/phthalate class Recently in 2013, researchers in Russia pointed that the amount of esters (EB, DNBP) adsorb on $\mathrm{MgCl}_{2}$ surface are in similar amounts (280umol/g) while 1,3-diethers (DIPDMP or DIBDMP) (Fig. 4) adsorb in relatively smaller amounts (approx. 25\% less) by adopting the general protocol for support synthesis [82]. This result gives a contradictory picture that less adsorption capacity of 1,3-diether relative to esters is the generic feature of 1,3-diether and substituents size in position 2 of 1,3-diether does not have influence in the adsorption behavior on $\mathrm{MgCl}_{2}$ surface. They also stipulated that unoccupied sites are present in the samples containing 1,3 diether, thus further treatment of 1,3-diether adsorbed samples with esters (EB or DNBP) showed the adsorption of these esters on the unoccupied sites (revealed from chemical analysis). In the case of EB adsorbed 1, 3-diether sample, there exist no change in diether quantity. This result clearly typified that there exists some unoccupied sites in $\mathrm{MgCl}_{2}$ surface available for ester adsorption and also some sites are not the right place for chelate coordination by 1,3 -diethers and also it cannot be ruled out that some neighboring sites of adsorbed 1, 3-diethers prevent the adsorption of esters. However, DNBP adsorbed 1, 3-diether sample shows a reduction in diether content, which is due to the fact that DNBP competes with diether for the same site. They tested the competitive effect of esters and 1,3-diethers for $\mathrm{MgCl}_{2}$ surface by performing experiments with pair of internal donors (EB/ DIBDMP, DNBP/DIBDMP). In the sample prepared from EB/DIBDMP, EB does not show any influence in the adsorption of DIBDMP. This showed that DIBDMP forms stronger complex with $\mathrm{MgCl}_{2}$ surface. In the case of simultaneously adsorbing DNBP and DIBDMP, it was found that more than half-adsorbed donors being accounted by DNBP. This verified that complex strength of DNBP is not lower than that of DIBDMP and thus DNBP competes with DIBDMP for surface sites.

\section{Succinate internal donors}

Succinate type IDs (Fig. 3) with quite low hydrogen response are particularly applied for iPP with large MWD. For this type of IDs, owing to ester bonds, leaching is quite significant in the presence of cocatalyst. The EDs would normally add to this catalyst to maintain stereo specificity of the polymer formed and the appropriate selection of
EDs is required for fine tuning to improve the isotacticity of the PP [83]. PP grades from this catalyst have good processability with applications like injection molding and pipes. Basell reported many specific substituted succinates compounds like din-butyl succinate (DBS), diethyl cyclohexyl succinate(DECS), diethyl-2-ethyl2-methyl succinate (DEEMS), diethyl-2,3-diisopropyl succinate (DEDPS) and diisobutyl-2,3-disopropyl succinate (DBDPS) as IDs (Fig. 4) in ZN catalysts [84]. Like diethers, here also sterically hindered derivatives were found to be having increased activity and high isotacticty. The activity of DBS as ID showed $530 \mathrm{~kg} / \mathrm{g} \mathrm{Ti}$, and the isotacticity of the obtained polymer was $96.2 \%$; while DEDPS and DBDPS catalysts have their activity 2333 (isotacticity: $98.5 \%$ ) and 2533 (isotacticity: $98.8 \%$ ) KgPP/ gTi respectively. J-Y Dong investigated different derivatives of 9,10-dihydroanthracene-9,10- $\alpha, \beta$-alkylsuccinates for isotactic polypropylene with and without $\mathrm{ED}$, and observed that proper molar ratio of support and ID, and also molar rate of ED and Ti are the triggering factors for improvement in activity as well as isotacticity [85]. Among the tested derivatives, ethyl and isobutyl versions were found to shown broad MWD (PDI: 10.9-11.5).

The properties of obtained polypropylene with the aid of phthalate, diether and succinate internal donors is compared and given as Table $2[86,87]$.

\section{Coordination mode of internal donors on $\mathrm{MgCl}_{2}$ support}

Different IDs have varying preferences on binding on different planes of $\mathrm{MgCl}_{2}$ surface, the prominent factors on binding includes $\mathrm{O}-\mathrm{O}$ distances, functionality of IDs, substitution patterns on ID. In $\mathrm{MgCl}_{2}$ the two lateral planes (110) and (104) are coordinately unsaturated with four and five coordinated $\mathrm{Mg}^{2+}$ ions [35]. 1,3-Diethers have better affinity towards (110) $\mathrm{MgCl}_{2}$ surface as compared to other IDs. Thus 1,3-diether was formed relatively higher on (110) $\mathrm{MgCl}_{2}$ surface rather than (104) surface while phthalate donors have affinity on both (110) and (104) surface [53, 88, 89] (Fig. 5).

In the case of 110 faces of $\mathrm{MgCl}_{2}$ layer, two types of coordination geometry of 1,3-diether are visible [74-76, 77-79]. One of them represents 110 chelate in which both oxygen atoms of the diether coordinated to a single $\mathrm{Mg}$ atom while in the other representing 110 bridge two oxygen atoms of the donor bond to two vicinal $\mathrm{Mg}$ atoms. For 1,3-Diether 110 bridge geometry is found to be higher in energy (more than $10 \mathrm{kcal} / \mathrm{mol}$ ) with respect to 110 chelate geometry. This is because of the inability of 1,3-diether moiety to stretch in order to coordinate to two $\mathrm{Mg}$ atoms in vicinal positions which are 
$6 \AA$ apart. The reverse is the case for phthalate type donors where 110 bridge is found to be lower in energy with respect to its 110 chelate mode of coordination.

Researchers have pointed out various explanation on the influence of IDs on catalyst stereo specificity based on their experimental and theoretical calculations. By considering many reports on this basis, here we categorized and collate the findings into a few hypothesis.

Hypothesis I In some studies two types of active sites; type I (unstable and poorly isospecific) and type II (stable and highly isospecific) on $\mathrm{MgCl}_{2}$ were categorized and both exhibited in a balanced form without the presence of ED. The introduction of ID (diether) removes out part of the unstable type 1 active site and new defects are formed on $\mathrm{MgCl}_{2}$ surface; where reform the stable type II active site leading to the generation of a new equilibirium between type I, type II and ID [27]. Overall the introduction of ID enabled to the decrease in Ti content and also the active sites, however the number of type II sites increases. Thus the addition of Lewis base on $\mathrm{MgCl}_{2}$ supported $\mathrm{TiCl}_{4}$ system increases the isotacticity of PP.

Hypothesis II The one hypothesis on the role of IDs in supported ZN catalysis for stereospecificity of polymer is to bring the aspecific centers inactive for polymerization. This is achieved by $\mathrm{TiCl}_{4}$ not coordinated to these aspecific centers. The IDs get capped on these centers, thus inaccessible for the entry of Ti species towards aspecific centers.

Hypothesis III Many other hypothetical understanding were laid down from DFT study on the adsorption of both $\mathrm{TiCl}_{4}$ and ID on $\mathrm{MgCl}_{2}$ surface. III a) Busico et al. postulated that two faces 100 and 110 have different acidities with 110 face being more acidic [90, 91]. From the experimental and theoretical calculations, they pointed out that $\mathrm{TiCl}_{4}$ have the ability to displace IDs from 100 face which are more basic, where binuclear stereospecific centres can be formed. Similar type of statements were drawn by Bukatov et al. on the basis of number of active sites on the catalysts with different electron donors [56]. III b) Monaco et al. [92] from their theoretical calculations postulated that 110 planes of $\mathrm{MgCl}_{2}$ are the preferential sites for $\mathrm{TiCl}_{4}$ and $\mathrm{TiCl}_{3}$ species adsorption with respect to 100 lateral cuts. However on the lateral cut 100 , the most energetically favoured species is $\mathrm{Ti}_{2} \mathrm{Cl}_{8}$ while monomeric and $\mathrm{Ti}_{2} \mathrm{Cl}_{6}$ species are energetically unfavored. Further to monomeric and dimeric species, they also postulated polynuclear Ti(III) species are energetically favoured. These findings are in good agreement with the initial results on generation of polynuclear titanium chloride [93, 94]. III c) Recently D'Amore et al. [95] investigated the adsorption of $\mathrm{TiCl}_{4}$ on $\mathrm{MgCl}_{2}$ surface by periodic hybrid DFT methods and claimed that adsorption of $\mathrm{TiCl}_{4}$ on $104 \mathrm{MgCl}_{2}$ sites are too weak, with the contradiction of earlier concept on many decades as 104 sites being the most prominent site for PP stereocatalysis. Very recently a new surface 015 for the coordination of $\mathrm{TiCl}_{4}$ has been discovered and is quite similar to traditional pentacoordinate one with distorted $\mathrm{Cl}-\mathrm{Mg}-\mathrm{Cl}$ bonds. Under the presence of adsorbate, this 015 site plays unusual flexibility by detaching $\mathrm{Mg}$ cations with chlorine underneath leading to unsaturated site for $\mathrm{TiCl}_{4}$ coordination [96]. III d) Taniike and Terano [97] described that mononuclear Ti centres on 110 magnesium surface are inefficient to identify the PP chain growth orientation in donor's absence and are totally aspecific. They also pointed out that diether donors preferentially adsorb on $110 \mathrm{MgCl}_{2}$, while mono and diester type of donors favorably adsorb on 110 and $100 \mathrm{MgCl}_{2}$ surfaces respectively. In the case of $\mathrm{EB}$ donor, aspecific mononuclear $\mathrm{Ti}$ species are dramatically modified to isospecific ones and also inhibits the phenomena of chain transfer to propylene leading to chain growth at mononuclear Ti species. Yet another periodic DFT study also pointed that diesters adsorb equally on 104 and $110 \mathrm{MgCl}_{2}$ surface and adopt stable chelate coordination on 110 plane; and they reconstruct $\mathrm{Mg}$ site while adopting chelate coordination on 104 surface. On the other hand for diether, chelate coordination on 104 site undergo reconstruction of $\mathrm{Mg}$ site and 110 surface is the stable site for chelate coordination [98]. In a recent study [29-34] Ti Solid state NMR spectra together with DFT calculations were utilized to investigate the local structure of $\mathrm{TiCl}_{4}$ adsorbed on $\mathrm{MgCl}_{2}$ surface [99].

Hypothesis IV Another hypothesis on the role of IDs for catalyst stereospecificity is their efficiency in transforming low isospecific sites into highly isospecific sites. This could be achieved by introducing sterically hindered groups on ID moiety [100, 101]. Steric hindrance of the coordinated donor in the nearby active Ti center is responsible for the formation of isospecific $\mathrm{MgCl}_{2}$ sites. However, this process of improving stereo specificity could be decreased by the addition of cocatalyst during polymerization as cocatalyst partly removes ID from the catalytic surface. In the case of diether as ID, this mode of removal by cocatalyst is very insignificant as diether strongly bond on the $\mathrm{MgCl}_{2}$ surface especially at 110 face.

\section{Non phthalate internal donors}

\section{Glutarates}

Glutarates are also applied as non phthalate ID for supported ZN system [102, 103]. Among the glutarate family, $\alpha$-substituted glutarates and $\beta$-substituted glutarates 
a
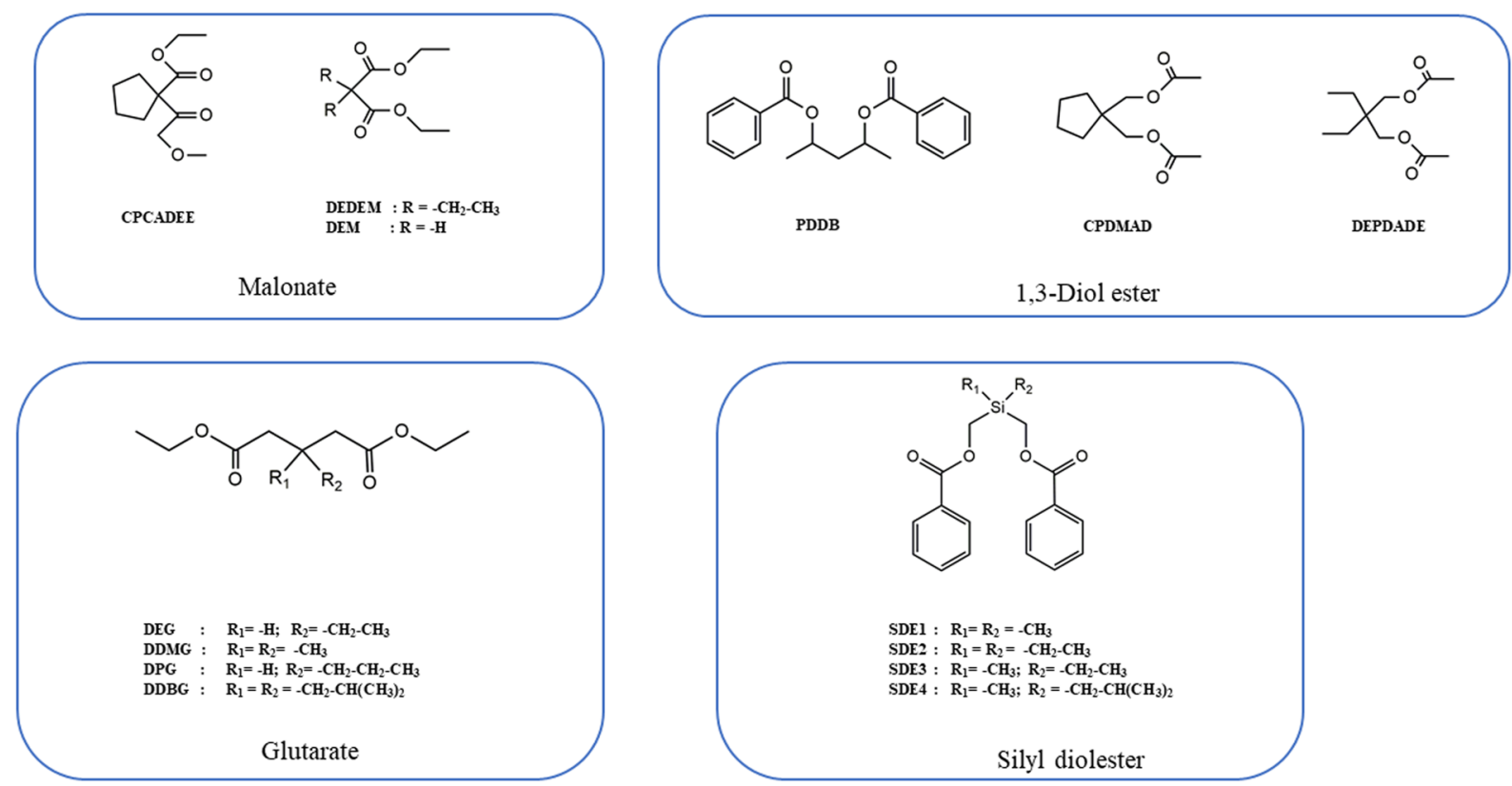

b
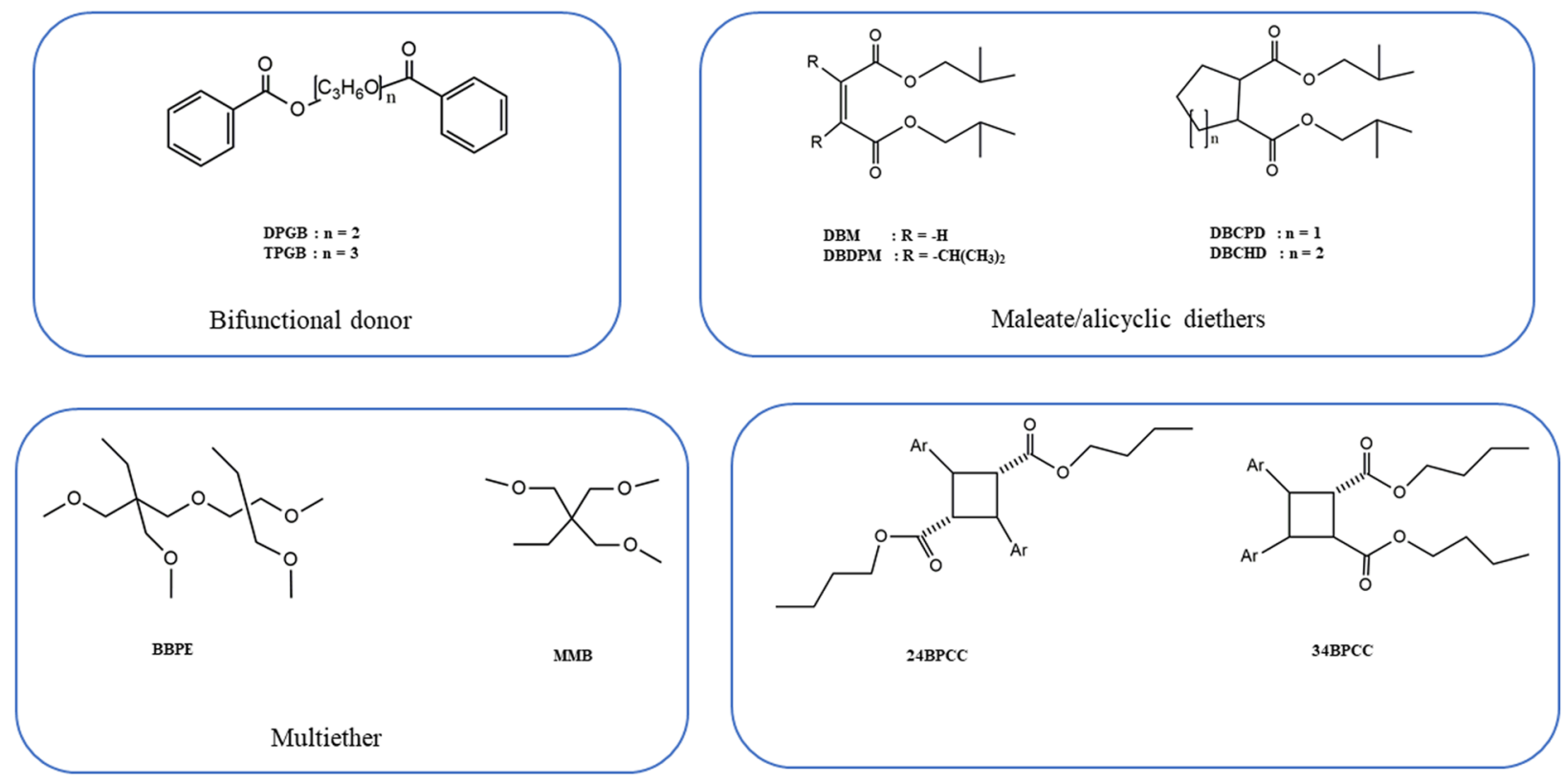

Fig. 6 (a) Non phthalate based IDs: glutarates, silyl diol ester, malonates, 1,3-diol ester, (b) Non phthalate based IDs: bifunctional, maleic/alicyclic diester, multiether, ecofriendly IDs

are mostly studied. A few typical examples of $\beta$-substituted glutarates as ID are diethyl-3-ethyl glutarate (DEG), diethyl-3-npropyl glutarate (DPG), diethyl-3,3-dimethyl glutarate (DDMG) (Fig. 6a) etc. When di-substituted with larger substituents in glutaric acid esters groups are used, the activity was found to be higher than with single substituted groups. Diethyl-3,3-diisobutyl glutarate (DDBG) (Fig. 6a) showed highest activity of $61 \mathrm{~kg} / \mathrm{g}$. cat with XI: 98\%. The highest isotacticity was found for DDMG with XI: 98.7\% [104].

\section{Silyl diol esters}

Recently silyl diol esters (SDE) were also reported [105] as ID for the production of iPP. The catalyst system with these IDs provide high activity (25-42 kg/g.cat), high 
isotacticity (XS: 3.5-1.4\%), broad MWD (6-7). Four structurally different symmetrical and unsymmetrical SDEs (SDE 1-SDE 4) were studied with varying substituents on silyl backbone (Fig. 6a). The compounds structure is found to be different from conventional $4^{\text {th }}$ and $5^{\text {th }}$ Gen catalysts. A few representatives among this class showed isotacticity above $96.3 \%$ even in ED absence.

Another study on SDE revealed that catalytic activity increases with increase in $\mathrm{Mg} / \mathrm{SDE}$ ratio and reaches to a maximum at a particular $\mathrm{Mg} / \mathrm{SDE}$ [106]. The similar phenomenon was noted for II too. The authors utilized active site model proposed by Soga et al. [73] involving non-specific active site I having two vacancies and isospecific active site II with only one vacancy on $\mathrm{MgCl}_{2}$ surface for SDE behavior. Authors predicted that addition of SDE results in new equilibrium formed among active site I, site II and SDE. With the introduction of SDE, even though Ti content and overall sum of active sites decreased, the amount of active site II is increased resulting in improved activity and isotacticity. The addition of excess $\mathrm{SDE}(\mathrm{Mg} /$ $\mathrm{SDE}<6$ ), resulted in poisoning of isospecific site II leading to decline of activity.

\section{Malonates}

In the year 2012, Guo et al. [107] has used five new IDs derived from diethyl malonate (Fig. 6a) which comes under the class of non-phthalate diesters and were coordinated with $\mathrm{TiCl}_{4}$ and $\mathrm{MgCl}_{2}$ for the polymerization of propylene. The effect of ID on catalytic behavior includes ID structure's steric hindrance, position of carbonyl groups, coordination capability of oxygen and oxygen atoms distance were investigated. Ti content (6.1\%) of 1,1-cyclopentanecarboxylic acid diethyl ester (CPCADEE) is little higher than (diethyl malonate) DEM (5.4\%), this is in respect to larger steric hindrance of pentacyclic ring in CPCADEE structure (Fig. 6a). While considering 1,1-cyclopentanedimethanol acetic diester (CPDMAD) (Fig. 6a), which cannot load on $\mathrm{MgCl}_{2}$ due to two obvious reasons: 1) bigger steric hindrance imposed by carbonyl groups and pentacyclic ring, 2) the electron donating ability of CPDMAD is quite weaker. While comparing 2,2-diethyl diethylmalonate (DEDEM) (Fig. 6a) and CPCADEE, Ti loading of DEDEM (5.4\%) is lower than that of CPCADEE (6.1\%) which could probably be due to its poor coordination ability with respect to CPCADEE, even though steric hindrance of ethyl of DEDEM is smaller than that of CPCADEE and two oxygen atoms distance of DEDEM is smaller than that of CPCADEE. While comparing DEDEM with CPDMAD, coordination ability with $\mathrm{Ti}$ is almost similar, however oxygen atoms distance is quite less in case of DEDEM, making it more effective for $\mathrm{Ti}$ coordination with respect to
CPDMAD, which is demonstrated by high loading of $\mathrm{Ti}$ (5.4\%) as compared to CPDMAD (Ti: 5.0\%). 1,1-bisethoxymethyl cyclopentane (BEMP) ligand which has shortest oxygen atoms distance and highest electronegativity make the strongest Ti coordination, which was in agreement with high Ti loading (7.8\%). The catalyst system with these IDs were investigated for propylene polymerization with and without ED. It was observed that CPCADEE and 2,2-diethyl-1,3-propanediol acetic diester (DEPDADE) (Fig. 6a) catalysts, activity and polymer properties were improved by the addition of ED.

\section{1,3-diol esters}

In the year 2002, a new class of PP catalyst were introduced with 1,3-diol ester as IDs [108, 109]. The activity of ZN catalyst in which 1,3-diol ester compounds used as IDs gave high performance, easy to adjust the stereospecificity, without the use of ED. PP obtained has high isotacticity, wide relative MWD. In addition, changing the molecular structure of 1,3-diol ester substituents on the structure can greatly change the hydrogen sensitivity of the catalyst. This type of catalyst has been used in a variety of polymerization process on industrial scale. For example 2,4-pentanediol dibenzoate (PDDB) [110] (Fig. 6a) was used as ID in ZN catalyst with activity $70-73 \mathrm{~kg} / \mathrm{gcat}$ and isotacticity $98.6 \%$.

\section{Mixed internal donors}

Several experiments on compatibility of incorporation of two different classes of IDs on supported ZN system were performed for the fundamental understanding of the catalyst behavior; and for learning, how it enables in tuning the catalyst for polymer properties with varying ratio of different IDs. While conducting mixed donor approach in ZN catalyst, it may be assumed that the new catalyst developed with ID having narrow or broad MWD would enable to tailor MWD by fine-tuning of IDs ratio. In this review, a very few typical examples of such studies are illustrated. Gao et al. [111] has demonstrated mixed IDs DIBP and PDDB towards catalyst activity, polymer isotacticity, microstructure and MWD. They prepared four catalysts; Cat A: No ID, Cat B:DIBP, Cat C: PDDB and Cat D: DIBP/PDDB and found that Cat D was having two times higher activity with respect to Cat B and Cat $\mathrm{C}$. With respect to kinetic behavior, propylene consumption rate follows the order $\mathrm{Cat} \mathrm{B}<\mathrm{Cat} \mathrm{C}<\mathrm{Cat} \mathrm{D}$ regardless of presence or absence of ED. In terms of isotacticity, mixed donor Cat-D functions high isotacticity, (II of PP has the highest value of $95.7 \%$ even without ED) similarly, diether does; makes it difficult to be removed from the catalyst even in the presence of cocatalyst. Even the donor content of Cat $\mathrm{D}$ was relatively much higher in the catalyst after treatment with $\mathrm{AlEt}_{3}$ while comparing with Cat B and Cat C. 
Another study was carried out by Makwana et al. [112] with two different classes of IDs (EB and DIBP) as a mixed donor approach with varying combinations of EB and DIBP. By optimal combination of these two donors, PP with tailored MW and MWD can be formed. The catalyst with higher DIBP provides narrow MWD, which might be due to more homogenous distribution of active sites. The improved productivity with increasing DIBP concentration is due to the fact that increased DIBP content stabilized the matrix. While demonstrating the kinetic profile of polymerization, DIBP alone follows steady kinetics whereas with increase in amount of EB, kinetic profile changes from steady state to decay state. With increase in amount of DIBP, higher Mn values (molecular weight higher with reduction in number of chains) are obtained indicating increased homogeneity in chain length distribution. However with increase in monoester content $\mathrm{Mw}$ increases (increase in the chain length and also number of chains), which may be due to the heterogeneity of active species in the support leading to random chain propagation.

Patil et al. [113] also introduced mixed ID approach using EB and sulfolane in anticipation of obtaining PP with broad MWD. Sulfalone is expected to have the variation in active species nature due to its linkage of $\mathrm{O}$ with $\mathrm{S}$ with respect to the linkage of $\mathrm{O}$ with carbon in EB. The productivity of the presented mixed donor catalyst is lower than EB class; which might be attributed to the modification of the active site of the catalyst pertaining to steric and electronic factors. However, there is no significant change in isotacticity and MFI while considering with EB class.

Song and Ihm [114] used phthalate (DIBP) and diether (DIBDMP) as mixed IDs for forming $\mathrm{MgCl}_{2}$ supported $\mathrm{ZN}$ system. It was identified from the composition study of the catalysts that not one donor is adsorbed on the surface exclusively, however diether content was found to be higher with respect to phthalate. This observation adds to the statement that 1,3-diether had a better affinity than phthalate for $\mathrm{MgCl}_{2}$.

\section{Bifunctional internal donors}

Chen et al. have synthesized [115] a new $\mathrm{MgCl}_{2}$-supported $\mathrm{TiCl}_{4}$ catalyst in combination with bifunctional donors such as di(propylene glycol) dibenzoate (DPGB) and tri(propylene glycol) dibenzoate (TPGB) (Fig. 6b) and compared with classical DIBP. The Ti content of the catalyst is higher in the case of DIBP with respect to bifunctional ID. Both DPGB and TPGB showed similar activity typifying that ester group chain length has less effect on catalytic activity and their activity is higher than DIBP catalyst. As described by Correa et al. [116] the coordination strength of ID follows the order; DPGB $\sim$ TPGB $>$ DIBP. This evidence further gave a confirmation that catalytic activity was generally influenced by ID type. Both DPGB and TPGB catalyst showed II value 98.8 and $98.5 \%$ slightly higher than that of DIBP catalyst having the value $98.2 \%$. While looking into the morphologies of these catalysts, both DPGB and TPGB donor have loose structure with respect to DIBP catalyst which might be attributed to chain flexibility in DPGB and TPGB donor. Both DPGB and TPGB donors exhibit PP with similar MW and their values are lower than that of DIBP catalyst. And also bi-functional IDs provide broadened MWD with respect to DIBP catalyst. Further, with the increase in the ether chain length, decrease in Mw and MW broadening were observed. This behavior on bifunctional catalyst might be due to different active sites on the catalyst surface.

\section{Maleate/alicyclic diesters}

In the year 2014, Dang et al. [117] have reported a new class of diesters as IDs, for propylene polymerization. The two IDs, diisobutyl maleate (DBM) and diisobutyl 2,3-diisopropylmaleate (DBDPM) comes under maleate class and the other two donors diisobutyl cyclohexane1,2-dicarboxylate (DBCHD) and diisobutyl cyclopentane1,2-dicarboxylate (DBCPD) comes under alicyclic ester groups (Fig. 6b). The catalysts prepared with these donors were used in propylene polymerization and their activity was compared with the catalyst prepared using DIBP. Catalysts with these four donor molecules have similar $\mathrm{Ti}$ content with respect to phthalate catalyst. However, donor content of this class of IDs was found to be lower than that of DIBP catalyst. PP isotacticity of these catalysts ranges from $83.5-97.1 \%$. These catalysts exhibited lower MW with broad MWD while comparing with DIBP catalyst. Catalyst with DBDPM, DBCPD and DIBP were found to be suitably better candidates as diesters in terms of isotacticity and polymerization performance; would be more in accordance with steric effects which follow the order DBCHD $>$ DBDPM $>$ DIBP-DBCPD $>$ DBM. It is concluded that IDs with isopropyl substituents on the ortho position of the ester function in diester compounds is found to enhance the polymerization activity and also raise the isotacticity of PP. It is also concluded that cyclopentanyl is a better candidate than cyclohexyl in diesters in improving the performance of the catalysts.

\section{Multi ether internal donors}

Mostly literatures on ether compounds as IDs are based on two methoxy groups. Zehadi et al. [118] used first multi ether ID 1-(2,2-bis(methoxymethyl)butoxy)-2,2bis(methoxymethyl)butane penta-ether (BBPE) (Fig. 6b) for testing the synthesis of iPP. They prepared series of catalysts (Cat A-Cat D) with varying amount of ID/Mg ratio and 
investigated the optimal behavior by varying $\mathrm{ID} / \mathrm{Mg}$ ratio for getting varying donor incorporation (ID/Mg: 0.07(CatA), 0.13 (Cat-B), 0.21 (Cat-C), 0.29 (cat-D)). The range of titanium contents were 3.1-3.4 wt \%. The highest activity was observed in Cat $\mathrm{C}$ with optimum ID/Mg ratio equal to 0.21 among the penta ether catalysts and the activity with and without ED decrease in the order; Cat 0 (one without ID) $>$ Cat C $>$ Cat D $>$ Cat B $>$ Cat A. These catalysts typically behave like diether class of compounds in terms of isotacticity, even without EDs these penta ether catalysts show good isotacticity compared to Cat $\mathrm{ZN}$ (phthalate based). Penta ether catalyst provides low Mw with high MFI while comparing with Cat $\mathrm{ZN}$; indicating increased hydrogen response ability for penta ether catalyst. With and without $\mathrm{ED}, \mathrm{Mw}$ and MWD of PP decreases in the order Cat A $>$ Cat $\mathrm{D}>$ Cat $\mathrm{C}>$ Cat $\mathrm{B}>$ Cat 0 and Cat $0>$ Cat $\mathrm{B}>$ Cat $\mathrm{D}>$ Cat $\mathrm{A}>\mathrm{Cat} \mathrm{C}$ respectively. Among the pentaether catalysts with and without $\mathrm{ED}$, Cat $\mathrm{C}$ is the one, which produces narrow MWD, while Cat B with broad MWD and lowest Mw.

The same group also investigated, a new tri-ether compound namely 1-methoxy-2, 2-bis(methoxymethyl)butane (MMB) (Fig. 6b) as ID and prepared a series of catalysts (Cat A-D) with varying amount of ID for iPP synthesis with and without the aid of ED [119]. The experiments were compared with Cat 0 , the one without ID. The titanium content (2.6-3.3\%) of the catalyst, Cat A-D (ID/Mg: 0.11 (Cat A), 0.22 (Cat B), 0.33 (Cat C), 0.44 (Cat D)) are almost similar to each other, and a slight reduction is observed from Cat 0 -Cat $\mathrm{D}$, which is due to increase in content of ID. This is probably due to the occupancy of IDs on more coordination sites of $\mathrm{MgCl}_{2}$ on which titanium would otherwise coordinate. The isotacticity of PP produced from Cat B-D are higher than that of conventional ZN catalyst with DIBP as ID. The activity of the catalyst with triether ID follow the order Cat $0>$ Cat B $>$ Cat C $>$ Cat D $>$ Cat A and Cat $0>$ Cat $\mathrm{B}>\mathrm{Cat} \mathrm{D}>\mathrm{Cat} \mathrm{C}>\mathrm{Cat} \mathrm{A}$ respectively. Decreased catalytic activity with the addition of ID and ED is poisoning of aspecific active sites of the catalyst while isotacticity of the PPs increased. It was observed that for triether ID, optimal value for ID/Mg is 0.22 for showing the highest activity (obtained in the case of Cat B). The lowest activity was observed for Cat A with ID/Mg ratio: 0.11 with and without ED. Catalyst with triether ID with the aid of ED is exhibiting good hydrogen response, have low MW with respect to conventional $\mathrm{ZN}$ catalyst and typically all these catalysts produce $\mathrm{PP}$ with narrow MWD.

\section{Eco friendly internal donors from bioresources}

Since phthalate, IDs pose potential health risk on their use in plastics, recently significant efforts have directed to ecofriendly electron donors which generally derived from biological resources too. Zhou et al. groups synthesized catalyst with ecofriendly salicyclic acid esters (SID) as IDs for iPP [120]. Salicylic acid which occurs as free acid or esters in many plant species and also an ingredient of aspirin; well known drug for aches. They synthesized and used five salicylates with structurally differ in hydrocarbon substituents as ecofriendly IDs. Authors judicially explained multi type active centres for SID catalysts from the analysis of wide PDI of PP (5.15-7.19) as the single active centres would generally bring narrow MWD (2-3). They pointed two key features from GPC results of PP produced with SID and DIBP catalysts-1) relative content of similar type of active centres that would bring similar MW vary in different SID catalysts, 2) MW produced by SID catalysts (SID 1-5) is lower than that of DIBP catalysts and also MW obtained from each kind of active sites in SID catalysts is different from that of DIBP catalyst illustrating active centres of both DIBP and SID catalysts were different. With respect to activities, SID catalysts with proper volume was shown to have better performance than DIBP catalysts. Another harmless bio derived diesters of alpha truxillic acid and beta truxinic acid (having anti-microbial, anti-inflammatory effects): dibutyl 2,4-diphenylcyclobutane-1,3-dicarboxylate (24BPCC) and dibutyl 3,4-diphenylcyclobutane-1,3dicarboxylate (34BPCC) developed for their use as ID (Fig. 6b) by Mattaa et al. was found to behave like phthalate ID with similar activity and isotacticity along with similar broad MWD [121]. These bio derived diesters shown opposite $\mathrm{H}_{2}$ response -MWD enlargement in presence of $\mathrm{H}_{2}$, which would be of industrial significance. Very recently Jiaojiao Zhang et al. reported novel ecofriendly ester based IDs called maleic rosinate tri-n-butyl and maleic rosinate tri-n-octyl derived from forest resources having anticancer and anti-inflammatory values [122]. These IDs showed the isotacticity up to $97.85 \%$ and also featured high optical transparency of the produced PP with $93.8 \%$ light transmittance and $4.4 \%$ haze which otherwise can only be achieved with nucleating agent [123].

\section{Concluding remarks}

Magnesium based ZN catalyst system holds the highest share for the development of isotactic PP. The ingredients of the catalyst are $\mathrm{MgCl}_{2}$ as support for improving activity, $\mathrm{TiCl}_{4}$ as catalyst precursor for active species generation and Lewis bases as electron donors for tuning PP isotacticity. Both Academic and industrial research on supported $\mathrm{ZN}$ systems are continuously progressing and millions of tons of polypropylene are produced annually and are still in demand. Most of the commercial ZN catalysts are based on phthalate IDs which are of potential risk for environment and health. Thus there is a need for the development of non phthalate based $\mathrm{ZN}$ catalysts systems with increased 
activity and selectivity which could be achieved with the help of electron donor combinations. The present tutorial review represents the introduction on various classes of IDs; and also on different non phthalate based organic structures covering malonates, silyl diol ester, 1,3-diol ester, glutarates, multi ethers and bifunctional compounds tested by Researchers over the past decades. The coordination mode of different classes of IDs with special attention to diether and phthalate classes was also briefly discussed in this contest. Finally an introduction on mixed electron donor approach is also presented; a way to future strategies for tuning the PP catalyst with requisite performance. This review leaves a scope for the improvisation of the function of $\mathrm{ZN}$ catalyst system by way of designing new IDs with better performance with the aid of the knowledge of the already existing IDs as discussed here.

Funding Open access funding provided by Manipal Academy of Higher Education, Manipal.

Open Access This article is licensed under a Creative Commons Attribution 4.0 International License, which permits use, sharing, adaptation, distribution and reproduction in any medium or format, as long as you give appropriate credit to the original author(s) and the source, provide a link to the Creative Commons licence, and indicate if changes were made. The images or other third party material in this article are included in the article's Creative Commons licence, unless indicated otherwise in a credit line to the material. If material is not included in the article's Creative Commons licence and your intended use is not permitted by statutory regulation or exceeds the permitted use, you will need to obtain permission directly from the copyright holder. To view a copy of this licence, visit http://creativecommons.org/licenses/by/4.0/.

\section{References}

1. Kaminsky W (2008) Trends in polyolefin chemistry. Macromol Chem Phys 209:459-466. https://doi.org/10.1002/macp.200700575

2. Maddah HA (2016) Polypropylene as a Promising Plastic: A Review. Am J Polym Sci 6:1-11. https://doi.org/10.5923/j.ajps.20160601.01

3. Song S, Feng J, Wu P et al (2009) Shear-enhanced crystallization in impact-resistant polypropylene copolymer: Influence of compositional heterogeneity and phase structure. Macromolecules 42:7067-7078. https://doi.org/10.1021/ma9004764

4. Oliani WL, Parra DF, Otaguro H et al (2007) Comparative Study of Polypropylene (HMS-PP) Degradation Under Different Conditions. The Polymer Processing Society 23rd Annual Meeting.

5. Suzuki E, Tamura M, Doi Y et al (1979) Molecular weight during polymerization of propene with the supported catalyst system $\mathrm{TiCl}_{4} / \mathrm{MgCl}_{2} / \mathrm{C}_{6} \mathrm{H}_{5} \mathrm{COOC}_{2} \mathrm{H}_{5} / \mathrm{Al}\left(\mathrm{C}_{2} \mathrm{H}_{5}\right)_{3}$. Die Makromolekulare Chemie 180:2235-2239

6. Jiang X, He A (2014) Stereospecific polymerization of olefins with supported Ziegler-Natta catalysts. Polym Int 63(2):179-183. https://doi.org/10.1002/pi.4633

7. Albizzati E, Parodi S, Barbe PC (1985) Components and catalysts for the polymerization of olefins. US patent 4522930

8. Giannini U, Cassata A, Longi P et al (1980) Process for the stereoregular polymerization of alpha-olefins. US patent 4187196
9. Luciani L, Kashiwa N, Barbe PC et al (1982) Catalysts for the polymerizing alpha-olefins and process for polymerizing alphaolefins in contact with said catalysts. US patent 4331561

10. Giannini U, Albizzati E, Parodi S (1979) Components of catalysts useful for the polymerization of $\alpha$-olefins, and catalysts prepared therefrom. US patent 4149990

11. Ratanasak M, Rungrotmongkol T, Saengsawang O et al (2015) Towards the design of new electron donors for Ziegler-Natta catalyzed propylene polymerization using QSPR modeling. Polymer 56:340-345

12. Xu D, Liu Z, Zhao J et al (2000) Highly active $\mathrm{MgCl}_{2}$-supported catalysts containing novel diether donors for propene polymerization. Macromol Rapid Commun 21(15):1046-1049. https:// doi.org/10.1002/1521-3927(20001001)21:15\%3c1046::AIDMARC1046\%3e3.0.CO;2-Y

13. Bukatov GD, Maslov DK, Sergeev SA et al (2019) Effect of internal donors on the performance of Ti-Mg catalysts in propylene polymerization: Donor introduction during or after $\mathrm{MgCl}_{2}$ formation. Appl Catal A 577:69-75. https://doi.org/10.1016/j.apcata.2019.03.010

14. Gao M, Liu H, Wang J et al (2004) Novel $\mathrm{MgCl}_{2}$-supported catalyst containing diol dibenzoate donor for propylene polymerization. Polymer 45:2175-2180. https://doi.org/10.1016/j.polymer. 2004.01.036

15. Liu B, Nitta T, Nakatani $\mathrm{H}$ et al (2003) Stereospecific Nature of Active Sites on $\mathrm{TiCl}_{4} / \mathrm{MgCl}_{2}$ Ziegler-Natta Catalyst in the Presence of an Internal Electron Donor. Macromol Chem Phys 204(3):395-402. https://doi.org/10.1002/macp.200390005

16. Shimozawa K, Saito M, Kataoka T et al (2002) Effect of internal donors in propylene polymerization analyzed with the two-site model. Polym Int 51(6):530-533. https://doi.org/10.1002/pi.879

17. Matsuoka H, Liu B, Nakatani H et al (2001) Variation in the isospecific active sites of internal donor-free $\mathrm{MgCl}_{2}$-supported Ziegler catalysts: Effect of external electron donors. Macromol Rapid Commun 22:326-328. https://doi.org/10.1002/15213927(20010301)22:5\%3c326::AID-MARC326\%3e3.0.CO;2-G

18. Wondimagegn T, Ziegler T (2012) The role of external alkoxysilane donors on stereoselectivity and molecular weight in $\mathrm{MgCl}_{2}$-supported Ziegler-Natta propylene polymerization: A density functional theory study. J Phys Chem C 116:1027-1033. https://doi.org/10.1021/jp2097789

19. Kojoh SI, Tsutsui T, Kashiwa N et al (1998) Effect of an external donor upon chain-transfer reactions in propylene polymerization with a $\mathrm{MgCl}_{2}$-supported titanium catalyst system. Polymer 39(25):6309-6313. https://doi.org/10.1016/S0032-3861(97) 10220-8

20. Khatri V, Sahoo U, Kaur S et al (2020) Control of Ziegler-Natta catalyst activity by the structural design of alkoxysilane-based external donors. New J Chem 44:6845-6852. https://doi.org/10. 1039/d0nj00039f

21. Zhou Q, Zheng T, Li H et al (2014) Effects of some new alkoxysilane external donors on propylene polymerization in $\mathrm{MgCl}_{2}$-supported Ziegler-Natta catalysis. Ind Eng Chem Res 53:17929-17936. https://doi.org/10.1021/ie5034123

22. Sacchi MC, Forlini F, Tritto I et al (1992) Activation Effect of Alkoxysilanes as External Donors in $\mathrm{MgCl}_{2}$-Supported ZieglerNatta Catalysts. Macromolecules 25:5914-5918

23. Natta G, Mazzanti G, Crespi G et al (1957) Stereoblock and isotactic propylene polymers. Chim Ind (Milan) 39:275-283

24. Moore EP (1996) Polypropylene Handbook: Polymerization, Characterization, Properties, Processing, Applications. Munich, New York: Hanser Publishers; Cincinnati: Hanser/Gardner Publications, cop

25. Hermans JP, Henrioulle P (1980) Catalytic complexes. US patent 4210738

26. Ziegler-Natta Catalysts, Kirk Othmer Encyclopedia of Chemical Technology. John Wiley and Sons Inc 26:502-554 
27. Natta G, Pasquon I, Zambelli A et al (1961) Highly stereospecific catalytic systems for the polymerization of $\alpha$-olefins to isotactic polymers. J Polym Sci 51(156):387-398. https://doi.org/10.1002/ pol.1961.1205115601

28. Tornqvist E, Seelback CW, Langer AW et al (1964) Preparation of partially reduced transition metal halide catalyst compositions. US Patent 3128252

29. Mayr A, Galli P, Susa E et al (1981) Catalysts for the polymerization of olefins. US patent 4298718

30. Koskinen J, Garoff T, Louhelainen J (1995) Preparation of Solid Ziegler Catalyst by Using a Multi-functional, Pivoting, Inclinable Reactor. US patent 5472923

31. Cho HS, Lee WY (2003) Synthesis of inorganic MgCl2-alcohol adduct via recrystallization method and its application in supported organometallic catalysts for the polymerization of ethylene with 1-hexene. J Mol Catal A: Chem 191:155-165. https:// doi.org/10.1016/S1381-1169(02)00215-7

32. Mayr A, Susa E, Giachetti E (1984) Catalysts for the polymerization of olefins US patent 4476289

33. Toyota A, Odawara K, Kashiwa N (1978) Process for preparing highly stereoregular polymers or copolymers of $\alpha$-olefins containing at least three carbon atoms, and catalysts used therefor. US patent 4085276

34. Noto VD, Bresadola S (1996) New synthesis of a highly active $\delta$ - $\mathrm{MgCl} 2$ for $\mathrm{MgCl} 2 / \mathrm{TiCl} 4 / \mathrm{AlEt} 3$ catalytic systems Macromol Chem Phys 197(11):3827 3835. https://doi.org/10.1002/macp. 1996.021971126

35. Mori H, Sawada M, Higuchi T et al (1999) Direct observation of $\mathrm{MgCl}_{2}$-supported Ziegler catalysts by high resolution transmission electron microscopy. Macromol Rapid Commun 20:245250. https://doi.org/10.1002/(SICI)1521-3927(19990501)20:5\% 3c245::AID-MARC245\%3e3.0.CO;2-R

36. Taniike T, Terano M (2007) Coadsorption and support-mediated interaction of Ti species with ethyl benzoate in $\mathrm{MgCl}_{2}$-Supported Heterogeneous Ziegler-Natta Catalysts Studied by Density Functional Calculations. Macromol Rapid Commun 28(18-19):19181922. https://doi.org/10.1002/marc.200700363

37. Sacchi MC, Tritio I, Shan C et al (1991) Role of the Pair of Internal and External Donors in $\mathrm{MgCl}_{2}$-Supported Ziegler-Natta Catalysts. Macromolecules 24(26):6823-6826. https://doi.org/10. 1021/ma00026a003

38. Soga K, Shiono T (1997) Ziegler-Natta catalysts for olefin polymerizations. Prog Polym Sci 22(7):1503-1546. https://doi.org/10. 1016/S0079-6700(97)00003-8

39. Kashiwa N, Ushida Y (1984) Process for polymerizing olefins. US patent 4442276

40. Albizzati E, Barbe PC, Noristi L et al (1990) Components and catalysts for the polymerization of olefins. US patent 4971937

41. Morini G, Albizzati E, Balbontin G et al (2006) 1,3-Dietheres and components and catalysts for the polymerization of olefins, containing said diethers. US patent 7049377

42. Morini G, Albizzati E, Balbontin G et al (2006) 1,3-diethers and components and catalysts for the polymerization of olefins, containing said diethers. US patent 7022640

43. Busico V, Chadwick JC, Cipullo R et al (2004) Propene/ethene-[1-13c] copolymerization as a tool for investigating catalyst regioselectivity. $\mathrm{MgCl}_{2} /$ internal donor/TiCl 4 -external donor/AlR 3 systems. Macromolecules 37(20):7437-7443. https://doi.org/10.1021/ma049104a

44. Morini G, Balbontin G, Gulevich YV et al (2006) Components and catalysts for the polymerization of olefins. EP patent 1088009:B1

45. Proto A, Oliva L, Pellecchia C et al (1990) Isotactic-specific polymerization of propene with supported catalysts in the presence of different modifiers. Macromolecules 23:2904-2907. https://doi.org/10.1021/ma00213a015
46. Noristi L, Barbe PC, Baruzzi G (1991) Effect of the internal/ external donor pair in high-yield catalysts for propylene polymerization. Die Makromolekulare Chemie 192(5):1115-1127. https://doi.org/10.1002/macp.1991.021920511

47. Barbe PC, Noristi L, Baruzzi G (1992) Effect of the internal/external donor pair in high-yield catalysts for propylene polymerization, $2^{\text {a) }}$. Polymerization results Die Makromolekulare Chemie 193(1):229 241. https://doi.org/10.1002/macp.1992.021930121

48. Busico V, Corradini P, Martino L (1986) Polymerization of propene in the presence of $\mathrm{MgCl}_{2}$-supported Ziegler-Natta catalysts, $2^{\text {a) }}$. Effects of the co-catalyst composition. Die Makromolekulare Chemie 187(5):1115-1124. https://doi.org/10.1002/macp.1986. 021870508

49. Yunxiang Xu, Lin J (1988) Research on polymerization catalysts. Shangan Petrochemical Industry 17(7):405-409

50. Zhang Q (1997) Supported efficient catalyst for propylene polymerization and the mechanism of electron donor. Combine Resin and Plastics 14(1):53-57

51. Keii T, Suzuki E, Tamura M et al (1982) Propene polymerization with a magnesium chloride supported Ziegler catalyst, 1. Principal kinetics Die Makromolekulare Chemie 183(10):2285-2304. https://doi.org/10.1002/macp.1982.021831001

52. Chadwick JC (2001) Advances in propene polymerization using $\mathrm{MgCl}_{2}$-supported catalysts. Fundamental aspects and the role of electron donors. Macromol Symp 173(1):21-36. https://doi. org/10.1002/1521-3900(200108)173:1/21::AID-MASY21/3.0. $\mathrm{CO} ; 2-\mathrm{A}$

53. Andoni A, Chadwick JC, Niemantsverdriet Hans JW et al (2008) The role of electron donors on lateral surfaces of $\mathrm{MgCl}_{2}$-supported Ziegler-Natta catalysts: Observation by AFM and SEM. J Catal 257(1):81-86. https://doi.org/10.1016/j.jcat. 2008.04.020

54. Weng Y, Jiang B, Fu Z et al (2018) Mechanism of internal and external electron donor effects on propylene polymerization with $\mathrm{MgCl}_{2}$-supported Ziegler-Natta catalyst: New evidences based on active center counting. J Appl Polym Sci 135(32):46605. https:// doi.org/10.1002/app.46605

55. Patil HR, Vyas PB, Bhajiwala HM et al (2012) Alkoxy Silanes as External Donors for Polypropylene Procatalyst: Study on Polymerization Performance and Effect on Resin Properties. PolymPlast Technol Eng 51:466-472. https://www.tandfonline.com/ doi/full/https://doi.org/10.1080/03602559.2011.65124

56. Bukatov GD, Zakharov VA, Barabanov AA (2005) Mechanism of olefin polymerization on supported Ziegler-Natta catalysts based on data on the number of active centers and propagation rate constants. Kinet Catal 46:166-176. https://doi.org/10.1007/ s10975-005-0065-0

57. Singh G, Kaur S, Makwana U et al (2009) Influence of internal donors on the performance and structure of $\mathrm{MgCl}_{2}$ supported titanium catalysts for propylene polymerization. Macromol Chem Phys 210(1):69-76. https://doi.org/10.1002/macp.200800486

58. Yang CB, Hsu CC, Park YS et al (1994) Infrared characterization of $\mathrm{MgCl}_{2}$ supported Ziegler-Natta catalysts with monoester and diester as a modifier. Eur Polymer J 30(2):205-214. https://doi. org/10.1016/0014-3057(94)90161-9

59. Potapov AG, Bukatov GD, Zakharov VA (2006) DRIFT study of internal donors in supported Ziegler-Natta catalysts. J Mol Catal A: Chem 246:248-254. https://doi.org/10.1016/j.molcata.2005. 11.016

60. Makwana U, Naik DG, Singh G et al (2009) Nature of phthalates as internal donors in high performance $\mathrm{MgCl}_{2}$ supported titanium catalysts. Catal Lett 131:624-631. https://doi.org/10. 1007/s10562-009-9981-3

61. Kissin YV, Liu X, Pollick DJ et al (2008) Ziegler-Natta catalysts for propylene polymerization: Chemistry of reactions leading 
to the formation of active centers. J Mol Catal A: Chem 287(12):45-52. https://doi.org/10.1016/j.molcata.2008.02.026

62. Arzoumanidis GG, Karayannis NM (1990) 12. Infrared characterization of supported propylene polymerization catalysts-A link to catalysts performance. Stud Surf Sci Catal 56:147-154. https://doi.org/10.1016/S0167-2991(08)61623-7

63. Arzoumanidis GG, Karayannis NM (1991) Infrared spectral characterization of supported propene polymerization catalysts. A link to catalyst performance. Appl Catal 76(2):221-231. https:// doi.org/10.1016/0166-9834(91)80049-3

64. Ystenes M, Rytter E (1992) Fourier transform infrared spectra of three titanium tetrachloride-ethyl benzoate complexes. Assignment based on five isotopic homologues and extension of the ethyl benzoate force field. Spectrochim Acta A: Mol Spectrosc 48(4):543-555. https://doi.org/10.1016/0584-8539(92)80045-X

65. Piovano A, D'Amore M, Thushara KS et al (2018) Spectroscopic Evidences for TiCl4/Donor Complexes on the Surface of MgCl2-Supported Ziegler-Natta Catalysts. J Phys Chem C 122(10):5615-5626. https://doi.org/10.1021/acs.jpcc.8b00903

66. Albizzati E, Barbe PC, Noristi L et al (1990) Components and catalysts for the polymerization of olefins. EP patent $0361494 \mathrm{~A} 2$

67. Morini G, Cristofori A (1996) Diethers suitable for use in the preparation of Ziegler-Natta catalysts. EP patent 0728724A1

68. Denkwitz Y, Schuster O (2020) High performance Ziegler-Natta catalyst systems and process for polymerization of olefins in the presence thereof. EP patent 3722332A1

69. Blaakmeer ESM, Antinucci G, Correa A et al (2018) Structural characterization of electron donors in Ziegler-Natta catalysts. J Phys Chem C 122(10):5525-5536. https://doi.org/10.1021/acs. jpcc.7b12667

70. Sacchi MC, Forlini F, Tritto I et al (1996) Polymerization stereochemistry with Ziegler-Natta catalysts containing dialkylpropane diethers: A tool for understanding internal/external donor relationships. Macromolecules 29:3341-3345. https://doi.org/10. 1021/ma9514232

71. Brambilla L, Zerbi G, Piemontesi F et al (2010) Structure of Donor Molecule 9,9-Bis(Methoxymethyl)-Fluorene in ZieglerNatta Catalyst by Infrared Spectroscopy and Quantum Chemical Calculation. J Phys Chem C 114(26):11475-11484. https://doi. org/10.1021/jp101354v

72. Morini G, Albizzati E, Balbontin G et al (2004) 1,3-Diethers and components and catalysts for the polymerization of olefins, containing said diethers. US patent $0235645 \mathrm{~A} 1$

73. Soga K, Shiono T, Doi Y (1988) Influence of internal and external donors on activity and stereospecificity of Ziegler-Natta catalysts. Die Makromolekulare Chemie 189(7):1531-1541. https:// doi.org/10.1002/macp.1988.021890708

74. Barino L, Scordamaglia R (1995) Steric equivalence between internal and external donors as polymerization stereoregulators: A molecular mechanics study. Macromol Symp 89(1):101111. https://doi.org/10.1002/masy. 19950890112

75. Busico V, Cipullo R, Monaco G et al (1999) High-Resolution 13C NMR Configurational Analysis of Polypropylene Made with $\mathrm{MgCl} 2$-Supported Ziegler-Natta Catalysts. 1. The "Model" System $\mathrm{MgCl} 2 / \mathrm{TiCl} 4-2,6-D i m e t h y l p y r i d i n e / A l(C 2 H 5) 3$. Macromolecules 32(13):4173-4182. https://doi.org/10.1021/ma981941n

76. Wada T, Taniike T, Kouzai I et al (2009) Propylene Polymerization Performance of Isolated and Aggregated Ti Species Studied Using a Well-Designed TiCl3/MgCl2 Ziegler-Natta Model Catalyst. Macromol Rapid Commun 30(11):887-891. https://doi.org/ 10.1002/marc. 200900015

77. Albizzati E, Giannini U, Morini G et al (1995) Recent advances in propylene polymerization with $\mathrm{MgCl}_{2}$ supported catalyst. Macromol Symp 89(1):73-89. https://doi.org/10.1002/masy. 19950890110
78. Stukalov DV, Zilberberg IL, Zakharov VA (2009) Surface species of titanium(IV) and titanium(III) in $\mathrm{MgCl} 2$-Supported Ziegler-Natta catalysts. A periodic density functional theory study. Macromolecules 42(21):8165-8171. https://doi.org/10.1021/ma901413b

79. Credendino R, Liguori D, Morini G et al (2014) Investigating Phthalate and 1,3-Diether Coverage and Dynamics on the (104) and (110) Surfaces of MgCl2-Supported Ziegler-Natta Catalysts. J Phys Chem C 118(15):8050-8058. https://doi.org/10.1021/ jp501390e

80. Morini G, Albizzati E, Balbontin G et al (1996) Microstructure distribution of polypropylenes obtained in the presence of traditional phthalate/silane and novel diether donors: a tool for understanding the role of electron donors in $\mathrm{MgCl}_{2}$-Supported Ziegler-Natta Catalysts. Macromolecules 29(18):5770-5776. https://doi.org/10.1021/ma960070j

81. Chadwick JC, van der Burgt FPTJ, Rastogi S et al (2004) Influence of Ziegler-Natta catalyst regioselectivity on polypropylene molecular weight distribution and rheological and crystallization behavior. Macromolecules 37(26):9722-9727. https://doi.org/10. 1021/ma048108c

82. Potapov AG, Politanskaya LV (2013) The study of the adsorption of 1,3-diethers on the $\mathrm{MgCl}_{2}$ surface. J Mol Catal A: Chem 368-369:159-162. https://doi.org/10.1016/j.molcata.2012.12. 004

83. Zhang HX, Lee YJ, Park JR et al (2011) Control of molecular weight distribution for polypropylene obtained by commercial Ziegler-Natta catalyst: Effect of electron donor. Macromol Res 19:622-628. https://doi.org/10.1007/s13233-011-0614-5

84. Morini G, Balbontin G, Vitale G (2004) Components and catalysts for the polymerization of olefins. WO patent $024785 \mathrm{~A} 1$

85. Wen X, Ji M, Yi Q et al (2010) Magnesium chloride supported Ziegler-Natta catalysts containing succinate internal electron donors for the polymerization of propylene. J Appl Polym Sci 118(3):1853-1858. https://doi.org/10.1002/app.32558

86. Vittoria A, Meppelder A, Friederichs N, et al (2017) Demystifying Ziegler-Natta Catalysts: The Origin of Stereoselectivity. ACS Catal 7(7):4509-4518. https://doi.org/10.1021/acscatal.7b01232

87. Pasquini N, Addeo A (2005) Polypropylene handbook (2ndEd.). Hanser Publishers: Munich, Germany

88. Vanka K, Singh G, Iyer D et al (2010) DFT Study of Lewis Base Interactions with the $\mathrm{MgCl}_{2}$ Surface in the Ziegler-Natta Catalytic System: Expanding the Role of the Donors. J Phys Chem C 114(37):15771-15781. https://doi.org/10.1021/jp106673b

89. Barino L, Scordamaglia R (1998) Modeling of isospecific Ti sites in $\mathrm{MgCl}_{2}$ supported heterogeneous Ziegler-Natta catalysts. Macromol Theory Simul 7:407-419. https://doi.org/10.1002/ mats.1998.040070404

90. Busico V, Corradini P, De Martino L et al (1985) Polymerization of propene in the presence of $\mathrm{MgCl}_{2}$-supported Ziegler-Natta catalysts, 1 . The role of ethyl benzoate as internal and external base. Die Makromolekulare Chemie 186(6):1279-1288. https:// doi.org/10.1002/macp.1985.021860617

91. Busico V, Corradini P (1989) Transition Metal Catalysed Polymerizations, ed. Quirk R.P. Cambridge University Press, Cambridge New York 551

92. Monaco G, Toto M, Guerra G et al (2000) Geometry and Stability of Titanium Chloride Species Adsorbed on the (100) and (110) Cuts of the $\mathrm{MgCl}_{2}$ Support of the Heterogeneous Ziegler-Natta Catalysts. Macromolecules 33:8953-8962. https://doi.org/10. 1021/ma000988h

93. Brant P, Speca AN (1987) Electron Spin Resonance, Titanium Oxidation State, and Ethylene Polymerization Studies of a Model-Supported Ziegler-Natta Catalyst. Spectroscopic Detection of Titanium Tetrachloride. Macromolecules 20(11):2740-2744. 
94. Brant P, Speca AN, Johnston DC (1988) Magnetic susceptibility study of a model supported Ziegler-Natta catalyst: Evidence for reduced titanium clusters. J Catal 113(1):250-255. https://doi.org/10.1016/ 0021-9517(88)90252-7

95. D’Amore M, Credendino R, Budzelaar PHM et al (2012) A periodic hybrid DFT approach (including dispersion) to $\mathrm{MgCl} 2$-supported Ziegler-Natta catalysts-1: TiCl4 adsorption on $\mathrm{MgCl} 2$ crystal surfaces. J Catal 286:103-110. https://doi.org/10.1016/j.jcat.2011.10. 018

96. D'Amore M, Thushara KS, Piovano A et al (2016) Surface Investigation and Morphological Analysis of Structurally Disordered $\mathrm{MgCl} 2$ and $\mathrm{MgCl} 2 / \mathrm{TiCl} 4$ Ziegler-Natta Catalysts. ACS Catal 6(9): 5786-5796. https://doi.org/10.1021/acscatal.6b00871

97. Taniike T, Terano M (2012) Coadsorption model for first-principle description of roles of donors in heterogeneous Ziegler-Natta propylene polymerization. J Catal 293:39-50. https://doi.org/10. 1016/j.jcat.2012.06.001

98. Shetty S (2016) Synergistic, reconstruction and bonding effects during the adsorption of internal electron donors and TiCl4 on $\mathrm{MgCl} 2$ surface: A periodic-DFT investigation. Surf Sci 653:5565. https://doi.org/10.1016/j.susc.2016.06.001

99. Iijimaa T, Shimizu T, Goto A et al (2019) ${ }^{47,49} \mathrm{Ti}$ solid-state NMR and DFT study of Ziegler-Natta catalyst: Adsorption of $\mathrm{TiCl} 4$ molecule onto the surface of $\mathrm{MgCl} 2$. J Phys Chem Solids 135:109088. https://doi.org/10.1016/j.jpcs.2019.109088

100. Sacchi MC, Forlini F, Tritto I et al (1995) Stereochemistry of the initiation step in Ziegler-Natta catalysts containing dialkyl propane diethers: A tool for distinguishing the role of internal and external donors. Macromol Symp 89(1):91-100. https://doi. org/10.1002/masy.19950890111

101. Hamedani NG, Arabi H, Poorsank F (2020) Towards the design of a mixture of diether and succinate as an internal donor in a $\mathrm{MgCl}_{2}$-Supported Ziegler-Natta catalyst. New J Chem 44:15758 15768. https://doi.org/10.1039/D0NJ02676J

102. Morini G, Balbontin G (2000) Components and catalysts for the polymerization of olefins. WO patent 55215

103. Mamoru K, Norio K, (1989) Process for production of olefin polymer or copolymer. EP patent 125911

104. Sandro P, Roberto N, Umberto G et al (1987) Components and catalysts for the polymerization of olefins. EP patent 45977A

105. Chen L, Leung TW, Tao T (2012) Procatalyst composition including silyl ester internal donor and method. US patent 8088872B2

106. Poorsank F, Arabi H, Hamedani NG (2019) Silyl diol ester as a new selectivity control agent in $\mathrm{MgCl}_{2}$-supported Ziegler-Natta systems for propylene polymerization: catalyst structure and polymer properties. RSC Adv 9:7420-7431. https://doi.org/10. 1039/c9ra00715f

107. Guo J, Hu G, Chen Z (2012) Synthesis of novel electron donors and their application to propylene polymerization. Transactions of Tianjin University 18:8-14. https://doi.org/10.1007/ s12209-012-1805-7

108. Mignogna A, Balboni D, Cristofori A et al (2012) Catalyst components for the polymerization of olefins. WO patent 0170138

109. Gao M, Wang J, Li C et al (2003) Polyol ester compounds useful in preparation of a catalyst for olefins polymerization, process for preparing the same and use thereof. WO patent 068723A1

110. Gao M, Liu H, Li Z (2003) Solid catalyst component for polymerization of olefins, catalyst comprising the same and use thereof. WO patent 068828
111. Gao F, Xia X, Mao B (2011) $\mathrm{MgCl}_{2}$-supported catalyst containing mixed internal donors for propylene polymerization. J Appl Polym Sci 120(1):36-42. https://doi.org/10.1002/app.31363

112. Makwana UC, Singala KJ, Patankar RB et al (2012) Propylene polymerization using supported Ziegler-Natta catalyst systems with mixed donors. J Appl Polym Sci 125(2):896-901. https://doi.org/ 10.1002/app.36239

113. Patil HR, Naik DG, Gupta V (2011) Broad Molecular Weight Polypropylene Synthesis using Mixed Internal Donor Incorporated Magnesium Dichloride Supported Titanium Catalyst. J Macromol Sci A 48(3):227-232. https://doi.org/10.1080/ 10601325.2011 .544937

114. Song BG, Ihm SK (2014) The role of two different internal donors (Phthalate and 1,3-Diether) on the formation of surface structure in $\mathrm{MgCl}_{2}$-supported Ziegler-Natta catalysts and their catalytic performance of propylene polymerization. J Appl Polym Sci 131(15). https://doi.org/10.1002/app.40536

115. Chen B, Zhang QF, Zhao LP et al (2013) Preparation and properties of isotactic polypropylene obtained from $\mathrm{MgCl}_{2}$-supported $\mathrm{TiCl}_{4}$ catalyst bearing bifunctional internal donor. Polym Bull 70:2793-2800. https://doi.org/10.1007/s00289-013-0988-y

116. Correa A, Piemontesi F, Morini G et al (2007) Key Elements in the Structure and Function Relationship of the $\mathrm{MgCl}_{2} / \mathrm{TiCl}_{4} /$ Lewis Base Ziegler-Natta Catalytic System. Macromolecules 40(25):9181-9189. https://doi.org/10.1021/ma071294c

117. Dang X, Li Q, Li H et al (2014) Ziegler-Natta catalysts with novel internal electron donors for propylene polymerization. J Polym Res 21:619. https://doi.org/10.1007/s10965-014-0619-9

118. Zahedi R, Taromi FA, Mirjahanmardi SH et al (2016) New Pentaether as the Internal Donor in the $\mathrm{MgCl}_{2}$-supported ZieglerNatta Catalysts for Propylene Polymerization. Chin J Polym Sci 34:268-279. https://doi.org/10.1007/s10118-016-1751-2

119. Zahedi R, Taromi FA, Mirjahanmardi SH et al (2016) Propylene Polymerization over $\mathrm{MgCl}_{2}$-Supported Ziegler-Natta Catalysts Containing Tri-Ether as the Internal Donor. Adv Polym Technol 37(1). https://doi.org/10.1002/adv.21651

120. Zhou Q, Wang A, Li H et al (2016) Microstructure of polypropylene and active center in Ziegler-Natta catalyst: effect of novel salicylate internal donor. RSC Adv 6:75023-75031. https://doi. org/10.1039/c6ra13819e

121. Mattaa A, Chammingkwana P, Singh BK et al (2018) Truxillic and truxinic acid-based, bio-derived diesters as potent internal donor in Ziegler-Natta catalyst for propylene polymerization. Appl Catal A Gen 554:80-87. https://doi.org/10.1016/j.apcata. 2018.01.030

122. Zhang J, Nan F, Yu H et al (2020) Direct Preparation of Transparent Isotactic Polypropylene with Supported ZieglerNatta Catalysts Containing Novel Eco-friendly Internal Electron Donors. Ind Eng Chem Res 59(19):8995-9003. https://doi.org/ 10.1021/acs.iecr.0c00387

123. Zhang YF, Chen H (2014) Effects of nucleating agent 1,3,5-benzenetricarboxylic acid tris(cyclohexylamide) on properties and crystallization behaviors of isotactic polypropylene. Colloid Polym Sci 292:493-498. https://doi.org/10.1007/ s00396-013-3098-3

Publisher's Note Springer Nature remains neutral with regard to jurisdictional claims in published maps and institutional affiliations. 